\title{
Zur württembergischen Sozialdemokratie am Anfang des 20. Jahrhunderts*
}

\author{
Von Malena Alderete
}

Als im April 1917 die Kontroversen innerhalb der deutschen Sozialdemokratie zur Gründung der Unabhängigen Sozialdemokratischen Partei Deutschlands (USPD) und damit zur Spaltung der Reichspartei führten ${ }^{1}$, war der Riss durch die württembergische Partei schon längst erfolgt. Bereits zwei Jahre zuvor, im Februar 1915, hatte sich die württembergische Sozialdemokratie infolge innerparteilicher Differenzen gespalten ${ }^{2}$. Diese entwickelten und verhärteten sich im Zuge fortwährender Debatten um Strategie und Taktik der politischen Praxis zwischen 1904 und 1914 - am Ende dieses zehnjährigen Differenzierungsprozesses ${ }^{3}$ standen sich „Reformisten“ und „Radikale“ in parteipolitischen Schlüsselfragen unversöhnlich gegenüber ${ }^{4}$. Schon vor Beginn des Ersten Weltkrieges führten die Kontroversen in

"Der vorliegende Aufsatz ist eine gekürzte Fassung der gleichnamigen Magisterarbeit, die am Historischen Institut der Universität Stuttgart im Januar 2010 abgeschlossen und von Herrn Prof. Dr. Hans-Peter Becht betreut wurde.

${ }^{1}$ Die Gründung der USPD erfolgte am 6./7. April 1917 auf einer Reichskonferenz der Parteiopposition in Gotha; vgl. Heinrich Potthoff und Susanne Miller: Kleine Geschichte der SPD: $1848-2002 .{ }^{8} 2002$. S. 78.

2 Vgl. Sylvia Greiffenhagen: Die württembergischen Sozialdemokraten im Ersten Weltkrieg und in der Weimarer Republik (1914-1933). In: Die SPD in Baden-Württemberg und ihre Geschichte. Von den Anfängen der Arbeiterbewegung bis heute (Schriften zur politischen Landeskunde Baden Württembergs 3). 1979. S. 160-191. S. 173.

${ }^{3}$ Von einem "Differenzierungsprozess" in der württembergischen Partei spricht auch Wilfried Sehm; vgl. Wilfried Sehm: Die Richtungskämpfe in der württembergischen Sozialdemokratie: 1908-1915. Zur Genese einer Parteispaltung. Unveröffentlichte Staatsexamensarbeit im Fach Geschichte. Universität Tübingen. 1979. S.7.

${ }^{4} \mathrm{Zu}$ den Begrifflichkeiten: „Reformisten“ und „Radikale“ sind zeitgenössische Bezeichnungen für Vertreter des jeweiligen politischen Kurses. Die Radikalen nannten die Reformisten oftmals auch „Opportunisten“ und warfen ihnen damit vor, für die Erlangung von kurzfristigen Zielen, die nicht selten mit persönlichen Vorteilen verbunden waren (wie etwa ein Mandat oder eine angesehene Position), gegen ihre politische Überzeugung zu verstoßen (im marxistischen Sprachgebrauch wird der Begriff heute weiter verwendet). In Anspielung an Bernsteins Theorien, wurden die Reformisten auch „Revisionisten“ genannt; demnach beschränkten sie sich auf Reformarbeit und hätten das Ziel einer revolutionären Umwälzung der kapitalistischen Gesellschaft aufgegeben. Die Radikalen, die sich selbst als „radikal“ 
der Landespartei schließlich zu heftigen organisatorischen Streitigkeiten. Dabei stritten beide Seiten vehement um den entscheidenden Einfluss auf die württembergische Partei.

Während die reformorientierten Sozialdemokraten die Mehrheit im Landesvorstand und in der Landtagsfraktion bildeten und ihre Anhänger vornehmlich in ländlich geprägten Ortsvereinen außerhalb größerer Industriezentren hatten, waren die radikalen Linken vor allem in den städtisch-industriell geprägten Ortsvereinen Stuttgart, Esslingen, Cannstatt ${ }^{5}$ und Göppingen vertreten ${ }^{6}$. Eine herausragende Rolle im w ürttembergischen Differenzierungsprozess spielten die Stuttgarter Partei und ihre revolutionären Wortführer; die prominentesten Vertreter waren Friedrich Westmeyer und Clara Zetkin. Jakob Walcher schrieb, dass „nirgends vielleicht Bremen ausgenommen - diese Auseinandersetzungen [über taktische und prinzipielle Fragen, die Verf.] in solcher Breite und mit solch prinzipieller Schärfe durchgefochten [wurden] wie in Stuttgart“. Das Bedeutendste sei zudem gewesen, dass alle Fragen "stets vor dem Forum der breiten Mitgliedermassen ausgetragen“7 wurden. Die Parteiversammlungen wurden zuvor in der „Schwäbischen Tag wacht“ - der Landespresse der württembergischen Sozialdemokraten - angekündigt, die dort erfolgte Diskussion wurde protokolliert und anschließend veröffentlicht.

Folgenreiche Auseinandersetzungen zwischen 1904 und 1914 waren die Debatten über den politischen Massenstreik (1904-1906, 1910), die Budgetbewilligung im Landtag $(1907,1908,1910)$, den Besuch der Landtagsfraktion beim König (1909) sowie die Kontroversen über die Antikriegsagitation im Vorfeld des Ersten Weltkrieges (1913-1914) ${ }^{8}$. In Stuttgart schloss sich im Verlauf der Debatten die Mehr-

oder „revolutionär“ bezeichneten, wurden von den Reformisten entweder auch „Radikale“ oder im abwertenden Sinn auch „Hyperradikale“ oder noch provokanter „Krakeeler“ genannt. Die Bezeichnung der radikalen Sozialdemokraten als „Linke“ und der reformorientierten als „Gemäßigte“ ist in der heutigen Literatur weit verbreitet. In der Darstellung wird mit den Begriffen „Radikale“ und „Linke“ sowie „Reformisten“ und „Gemäßigte“ operiert.

${ }^{5}$ Cannstatt wurde zwar im Jahr 1904 Stuttgart eingemeindet, konstituierte sich jedoch ab 1910 als eigener Ortsverein; vgl. Tätigkeitsbericht des Sozialdemokratischen Vereins in Stuttgart. Vom 1. Juli 1910 bis 30. Juni 1911. 1911. S. 20.

${ }^{6}$ Vgl. Maja Christ-Gmelin: Die württembergische Sozialdemokratie 1890-1914. Ein Beitrag zur Geschichte des Reformismus und Revisionismus in der deutschen Sozialdemokratie. 1976. S. 212.

${ }^{7}$ Jakob Walcher: Westmeyers Bedeutung für die kommunistische Bewegung. In: Erste Beilage zur Süddeutschen Arbeiter-Zeitung Nr. 265 vom 12.11. 1927. S. 5.

${ }^{8}$ Vor 1904 prägten das Parteileben die Zeit unter dem Sozialistengesetz (1878-1890) sowie die Diskussion über Bernsteins Revisionismus-Theorie (1898-1903); ausführlicher dazu: Malena Alderete: Die württembergische Sozialdemokratie zu Anfang des 20. Jahrhunderts. Die Stuttgarter „Radikalen“ im innerparteilichen Konflikt zwischen 1904 und 1914. Unveröffentlichte Magisterarbeit im Fach Geschichte. Universität Stuttgart. 2010. S. 12-20 und S. 28-36. - Die Zeit der Verfolgung unter dem Sozialistengesetz radikalisierte die Mitgliedschaft zwar insgesamt, die mildere Handhabung des Gesetzes in Württemberg gewährte aber den württembergischen Sozialdemokraten mehr Handlungsspielraum als in anderen Teilen des Reiches. Man konnte infolge dessen in Württemberg aus anderen Gebieten ausgewiesene 
heit der Mitgliedschaft dem radikalen Kurs an, wählte im Jahr 1908 Friedrich Westmeyer zum Parteivorsitzenden und widersetzte sich unter seiner Führung organisiert und geschlossen den reformorientierten Tendenzen in der Partei ${ }^{9}$.

Nachdem im Jahr 1911 die Stuttgarter Radikalen die Kontrolle über die Schwäbische Tagwacht erlangten, eskalierten die politischen Differenzen zu einem offenen Konflikt mit dem Landesvorstand ${ }^{10}$. Als nach Beginn des Ersten Weltkrieges die sozialdemokratische Reichstagsfraktion am 4. August den Kriegskrediten zustimmte ${ }^{11}$, fand sie ihre schärfsten Kritiker auch in den Reihen der Stuttgarter Sozialdemokratie. Die Stuttgarter Linken, die unablässig gegen den Krieg mobil machten, trugen maßgeblich zur reichsweiten Vernetzung oppositioneller Sozialdemokraten bei und bildeten schließlich die „Keimzelle der USPD“12, wie ihr parteipolitischer Gegner Wilhelm Keil sich später erinnern sollte.

Parteimitglieder aufnehmen oder die illegale Verbreitung der Zeitung organisieren. Vgl. dazu Christof Rieber: Das Sozialistengesetz und die Sozialdemokratie in Württemberg 1878-1890 (Schriften zur südwestdeutschen Landeskunde 19). 1984. - Der Revisionismusstreit wurde in Württemberg weniger scharf ausgetragen als in anderen Teilen des Reiches. Die Sitzungsprotokolle der Schwäbischen Tagwacht zeigen, dass man die Debatte darüber eher vermied, um nicht das Außenbild von Geschlossenheit zu gefährden. Die württembergische SPD unterstützte mit wenigen Ausnahmen den Dresdener Beschluss von 1903, der den Revisionismus ablehnte. Vgl. dazu auch Christ-Gmelin (wie Anm. 6) S. 128-131.

9 Westmeyer wurde am 10.2.1908 zum Vorsitzenden gewählt, der Landtagsabgeordnete Heymann verzichtete auf eine erneute Kandidatur; vgl. Hartmut Henicke: Der Kampf der Stuttgarter Linken gegen die opportunistische Zersetzung der Partei in den Jahren 19101914. 1985. S. 32. - Gezielte Maßnahmen der Radikalen festigten ihren Einfluss insbesondere in der Stuttgarter Partei. So gründeten sie in Stuttgart im Jahr 1910 ein Parteisekretariat und stellten einen besoldeten Parteisekretär ein, etablierten ein eigenes Vertrauensleutesystem, das u.a. die politische Arbeit in den Straßenzügen organisierte, verabschiedeten eine neue Satzung, die zur aktiven Parteiarbeit verpflichtete, und bauten die Organisationseinheiten in den Bosch-Werken aus; vgl. ebd. S.39-50. - Darüber hinaus engagierten sich die Radikalen in der Frauenbewegung und im Bereich Bildung und Soziales; die Wahl Westmeyers zum Landtagsabgeordneten im Jahr 1912 erweiterte schließlich ihren Einfluss auf die Landespartei; vgl. ebd. S. 173-202. - Maja Christ-Gmelin (wie Anm. 6) S.187f. und 192-195.

${ }_{10}$ Seit 1.10. 1911 stellten die Radikalen mit vier von sieben Mitgliedern die Mehrheit in der „Presskommission“. Die Presskommission entschied über die prinzipielle und taktische Haltung des Parteiorgans, sowie über die Einstellung von Redakteuren und deren Gehälter; vgl. Henicke (wie Anm. 9) S. 115. - Der Konflikt um die Ausrichtung der Schwabischen Tagwacht und der Besetzung der Tagwacht-Redaktion zog sich über mehrere Jahre; vgl. die Ausführungen von Henicke S. 92-128 (April 1911-Juli 1912) sowie S. 129-141 (Juli 1912-August 1914).

11 Vgl. Greiffenhagen (wie Anm. 2) S. $163 \mathrm{f}$.

12 Wilhelm Keil: Erlebnisse eines Sozialdemokraten. Bd.1. 1947. S. 322. 


\section{Mitglieder und Wähler der württembergischen Sozialisten}

Nach dem Verbot der Partei unter dem Bismarckschen Sozialistengesetz vollzog sich die Rückkehr in die Legalität vor dem Hintergrund einer beschleunigten Industrialisierung ${ }^{13}$. In Württemberg prägten große räumliche Disparitäten die Entwicklung; mit Ausnahme einzelner Industriezentren fiel das Land insgesamt weit hinter den Reichsdurchschnitt zurück ${ }^{14}$. Charakteristisch für Württemberg war die dezentrale Ansiedlung der Industrie, sie erstreckte sich bis in die Nähe ländlicher Gemeinden in den Gebieten der Realteilung. Dort gab es ein großes Angebot billiger Arbeitskräfte, die „Arbeiterbauern“, die neben dem landwirtschaftlichen Erwerb in die nächstgelegenen Städte zur Fabrikarbeit pendelten ${ }^{15}$.

Zum Zentrum der aufstrebenden Metallindustrie avancierte die Region Stuttgart, die neben der Landeshauptstadt die Gemeinden Esslingen, Ludwigsburg und Cannstatt umfasste ${ }^{16}$. In den letzten Jahren des 19. Jahrhunderts vergrößerte sich hier die städtische Arbeiterschaft erheblich und war anders als im ländlichen Raum zunehmend in Großbetrieben beschäftigt ${ }^{17}$. Kennzeichnend für die Lage der Arbeiterschaft waren prekäre Lebens- und Arbeitsverhältnisse, niedrige Löhne und

13 Knapp fünf Wochen nach Aufhebung des Sozialistengesetzes fand am 2. November 1890 die Gründungsveranstaltung des württembergischen Landesverbands in Stuttgart statt; vgl. Satzungen der Sozialdemokratischen Partei in Württemberg (beschlossen auf der Landesversammlung zu Stuttgart, am 2. November 1890). O.J. [1890]. - Gemessen am Bevölkerungswachstum von 0,33 Prozent war die Zunahme gewerblicher Beschäftigter mit 2,42 Prozent zwischen 1882 und 1895 überproportional hoch; vgl. Klaus Megerle: Württemberg im Industrialisierungsprozess Deutschlands. Ein Beitrag zur regionalen Differenzierung der Industrialisierung (Geschichte und Theorie der Politik A 7). 1982. S. 127.

14 „Die landwirtschaftliche Bevölkerung Württembergs“, Schwäbische Tagwacht Nr. 254 vom 31.10. 1899. S. 1.

15 Vgl. Megerle (wie Anm. 13) S. 147 und 241. - Theodor Bergmann, Wolfgang Haible und Galina Irwanowa: Friedrich Westmeyer. Von der Sozialdemokratie zum Spartakusbund Eine politische Biographie. 1998. S.28.

16 Bis zum Beginn des Ersten Weltkrieges wuchs die Region „zu einem Wirtschaftszentrum europäischer Bedeutung“ geprägt durch die Entwicklung von drei Unternehmen: die Maschinenfabrik Esslingen, die Robert-Bosch-Gesellschaft und die Daimler Motorengesellschaft; vgl. Gert Kollmer-von Oheimb-Loup: Die Anfänge der Industrialisierung im Neckarraum von 1850 bis zum Ende des 19. Jahrhunderts. In: 100 Jahre DaimlerChrysler. Werk Untertürkheim 1904-2004 (Wissenschaftliche Schriftenreihe 8). 2005. S. 49-67. S. 66 f.

17 34,7 Prozent der Großbetriebe Württembergs waren im Jahr 1895 in der Region Stuttgart ansässig, davon allein 23,5 Prozent in der Landeshauptstadt. 35.447 Personen arbeiteten dort in 1708 Großbetrieben; vgl. Megerle (wie Anm. 13) S. 145 ff. - Allein zwischen 1897 und 1900 stieg die Zahl der Arbeiter in Stuttgart von insgesamt 28.386 auf 32.241; vgl. Jahresbericht der Vereinigten Gewerkschaften für 1897/98, zitiert nach Theodor Leipart: Beitrag zur Beurteilung der Lage der Arbeiter in Stuttgart. Nach statistischen Erhebungen im Auftrage der Vereinigten Gewerkschaften. 1900. S.6. - Vierter Jahresbericht für das Geschäftsjahr 1900 nebst Geschäftsbericht des Vorstandes der Vereinigten Gewerkschaften Stuttgart. Hg. von Arbeiter-Sekretariat Stuttgart. O.J. [1900]. S. 38. 
lange Arbeitszeiten ${ }^{18}$. Genau diese Umstände prangerte die Sozialdemokratie an ${ }^{19}$ und mobilisierte so viele Arbeiter für ihre Ideen - seit der Neugründung im Jahr 1890 folgte ein Wahlerfolg dem anderen und die Mitgliederzahlen stiegen unentwegt ${ }^{20}$.

Zwischen 1904 und 1913 verdreifachte sich die Zahl der Stuttgarter Mitgliedschaft von 2875 auf 9954 Personen $^{21}$. Die Stuttgarter Partei, die sich in mehrere Bezirksvereine ${ }^{22}$ gliederte, war ausgesprochen proletarisch: Laut einer Berufsstatistik von 1908 waren von 4769 Mitgliedern 3546 in Industrie und Gewerbe tätig, darunter 1446 Metallarbeiter und 701 Holzarbeiter $^{23} .1912$ waren von 9157 Mitgliedern 3491 allein in der Holz- und Metallindustrie tätig. Intellektuelle waren kaum vertreten - laut Statistik nur zwei Ärzte und 17 Redakteure und Schriftsteller ${ }^{24}$.

18 Vgl. dazu die Studie von Leipart (wie Anm. 17). An der Befragung von 1897 beteiligten sich rund 33 Prozent der Arbeiter und 12 Prozent der Arbeiterinnen; vgl. ebd. S. 6.

${ }^{19}$ In einer Broschüre hieß es: „Die moderne Industrie hat ohne Zweifel Großes und Staunenswertes geleistet, aber sie hat auch die Ausbeutung der Arbeitskraft ins Unendliche gesteigert.“ Die Sozialdemokratie kämpfe für die Verbesserung des Loses der Arbeiter, „ihr werden und müssen sich die denkenden und vorwärts strebenden Arbeiter noch alle anschließen, in ihrem eigenen Interesse. Es lebe die Sozialdemokratie!"; zitiert nach Sozialdemokratie. Ein Mahnruf an das arbeitende Volk in Stadt und Land. 1891. S. 1, 5 und $19 \mathrm{f}$.

20 Zwischen 1891 und 1895 stiegen die Mitgliederzahlen der Landespartei von etwa 4000 auf 6000; vgl. Dieter Fricke: Handbuch zur Geschichte der deutschen Arbeiterbewegung 1869-1917. Bd.1. 1987. S. 307. - Bei den Reichstagswahlen vom 20. Februar 1890 errang die Sozialdemokratie in Württemberg 8,9 Prozent der Stimmen, reichsweit waren es 19,7 Prozent, die SPD wurde damit zur stärksten Wählerpartei im Kaiserreich. Der stetige Aufstieg hielt bis 1912 an, als die SPD schließlich 32,5 Prozent in Württemberg bzw. 34,8 Prozent reichsweit erhielt und mit 110 Abgeordneten die größte Fraktion im Reichstag wurde; vgl. Potthoff/Miller (wie Anm. 1) S. 57. Weitere Details über die Wahlergebnisse ebd.

21 Vgl. Geschäfts- und Tätigkeitsbericht für das Jahr 1907. Sozialdemokratischer Verein Stuttgart. 1907. S. 2. - Tätigkeitsbericht des Sozialdemokratischen Vereins in Stuttgart. Vom 1. Juli 1912 bis 31. März 1913. O.J. [1913]. S. 5.

221906 gab es zehn Bezirksvereine: Heslach, Westen, Süden, Norden, Stöckach, Prag, Berg, Ostheim, Gaisburg, Gablenberg; vgl. Geschäfts- und Tätigkeitsbericht für das Jahr 1906. Sozialdemokratischer Verein Stuttgart. 1906. S. 3.

${ }^{23}$ Die drittgrößte Gruppe in Industrie und Gewerbe nach den Metall- und Holzarbeitern waren 569 „Arbeiter, Tagelöhner, Hausdiener usw.“ vgl. Geschäfts- und Tätigkeitsbericht 1907 (wie Anm. 21) S. 17. - Die Statistik ist das Ergebnis einer Mitgliederbefragung. Von den mittlerweile 13 Bezirksvereinen fehlen die Daten des Vereins Gaisburgs. Unklar ist, ob die Befragten ihren erlernten Beruf angaben oder lediglich die ausgeübte Tätigkeit. Wie hoch der Anteil an Facharbeitern war, kann deshalb daraus nicht erschlossen werden.

${ }^{24}$ Vgl. Tätigkeitsbericht für die Zeit vom 1. Juli 1911 bis 30. Juni 1912. Sozialdemokratischer Verein Stuttgart. O.J. [1912]. S. 16f. 


\section{Der politische Massenstreik: Eines der „wirksamsten Kampfmittel“ der Arbeiterschaft?}

Mit Blick auf den Internationalen Sozialistenkongress in Amsterdam begann im Jahr 1904 in der deutschen Sozialdemokratie die Massenstreikdiskussion. Vor dem Hintergrund massiver Streikwellen der vergangenen Jahre sollten eine ausführliche Erörterung der Frage erfolgen und ein internationaler Beschluss gefasst werden ${ }^{25}$. Kerngedanke des politischen Massenstreiks war die Auffassung, dass ein großer Streik als Mittel dienen könne, um ein beschränktes, konkretes Ziel innerhalb des Kapitalismus zu erreichen ${ }^{26}$.

Anfangs dominierte vor allem eine Frage: War es möglich, sich vom anarchistischen Generalstreikgedanken abzugrenzen ${ }^{27}$ So waren Gegner des Massenstreiks der Meinung, allein eine mögliche Assoziation mit dem anarchistischen Generalstreik erfordere seine Ablehnung ${ }^{28}$. Außerdem könne ein Generalstreik die proletarische Bewegung aufs empfindlichste schädigen ${ }^{29}$. Befürworter, allen voran Clara Zetkin, hielten den Massenstreik für ein bedeutendes „Kampfmittel“, um das Wahlrecht zu verteidigen, und differenzierten diesen dabei ausdrücklich vom anarchistischen Generalstreik ${ }^{30}$.

25 Vgl. Internationaler Sozialistenkongress zu Amsterdam (14. bis 20. August 1904). In: Kongressprotokolle der Zweiten Internationale. Bd.1: Paris 1889-Amsterdam 1904. ND 1975. S. $24 \mathrm{f}$.

${ }^{26}$ Vgl. Edgar Weick: Theorien des Streiks. In: Zur Theorie und Praxis des Streiks. Hg. von Dieter Schneider. 1971. S. 97-154. S. 119. - Der zum Teil erfolgreiche Streik der belgischen Arbeiter für die Einführung des allgemeinen Wahlrechts im Jahr 1893 war dafür ein eindrückliches Beispiel; vgl. Heinz-Gerhard Haupt u. a.: Der Politische Streik - Geschichte und Theorie. In: Politischer Streik (Jahrbuch Arbeiterbewegung. Geschichte und Theorie). 1981. S. 13-53. S. 17 und 24. Weitere politische Streiks folgten in den Jahren 1902 (Belgien und Schweden), 1903 (Holland) und 1904 (Italien); vgl. ebd. S. 24f. - Zur Definition, Genesis und Funktion des politischen Streiks vgl. ebd. S. 16-25.

27 Anders als der politische Massenstreik sollte der anarchistische Generalstreik nicht etwa als Etappenziel zur Erreichung bestimmter Reformen zum Einsatz kommen, sondern den kapitalistischen Staat unmittelbar beseitigen und damit „nichts anderes als die soziale Revolution selbst" sein; vgl. Weick (wie Anm. 26) S.107. - Zu Beginn der Debatten wurde gemäß dem internationalen Sprachgebrauch meist nur von Generalstreik gesprochen und erst ab 1905 von Massenstreik. Der Begriff Massenstreik entsprach der deutschen Terminologie; vgl. Carl E. Schorske: Die grosse Spaltung. Die Sozialdemokratie 1905-1917. 1981. S. 56. Vermutlich wurde der Begriff Generalstreik gemieden, um eine Assoziation mit dem anarchistischen Generalstreikgedanken zu vermeiden.

${ }^{28}$ In der ersten in Stuttgart überlieferten Debatte erklärte der Landtagsabgeordnete Karl Hildenbrand, es sei weit verbreitete Meinung, dass, wenn der Generalstreik einmal möglich sei, auch die sozialistische Gesellschaft verwirklicht werden könnte. Deshalb müsse es als ausgeschlossen gelten, den Generalstreik ins Programm aufzunehmen; vgl. Schwäbische Tagwacht Nr. 181 vom 5. 8. 1904. S. 5.

${ }_{29}$ Vgl. die Beiträge der Abgeordneten Heymann und Sperka, Schwäbische Tagwacht Nr. 208 vom 6.9. 1904. S. 5.

30 Der oft zitierte Ausspruch „Generalstreik sei Generalunsinn“, so Zetkin, sei „völlig 
Auf dem Parteitag in Jena im Jahr 1905 wurde der politische Massenstreik schließlich erstmals reichsweit diskutiert ${ }^{31}$. Mittlerweile bekannte sich die II. Internationale zum politischen Massenstreik als möglichem Kampfmittel ${ }^{32}$. Im Vorfeld schrieb die Schwäbische Tagwacht, ein einfaches Bekenntnis zur Amsterdamer Resolution sollte in Jena genügen und die weitere Diskussion über den politischen Massenstreik vorerst geschlossen werden ${ }^{33}$. Demgegenüber legte der Stuttgarter Ortsverein auf dem Parteitag eine Resolution vor, in der man „die Diskussion des politischen Massenstreiks für durchaus geboten “34 halte. Clara Zetkin erklärte, innerhalb breiter Proletariermassen werde eine Antwort auf die Frage gesucht, ob neben den erprobten Mitteln des gewerkschaftlichen und parlamentarischen Kampfes unter bestimmten Ausnahmesituationen noch andere Kampfmittel zu Gebote stünden. Aufgrund dessen käme man um die Erörterung des politischen Massenstreiks nicht herum ${ }^{35}$.

In der Jenaer Debatte waren die Gegner des Massenstreiks deutlich in der Minderheit $^{36}$. Ähnlich den Äußerungen Sperkas und Heymanns in Stuttgart argumentierten sie, die streikenden Massen seien nicht imstande, die zu erwartende Polizeigewalt abzuwehren ${ }^{37}$. Mit Ausnahme des Abgeordneten Dr. Lindemann stimmten alle württembergischen Delegierten für die Jenaer Resolution, die „die umfassendste Anwendung der Massenarbeitseinstellung“ als eines „der wirksamsten Kampfmittel“ betrachtete, nicht nur um Angriffe auf die Arbeiter abzu-

verfehlt“. Das gelte wohl für den von den Anarchisten empfohlenen Generalstreik, nicht aber für den Generalstreik, wie ihn die Sozialdemokratie verstehe. In Anbetracht der „immer unverhüllter auftretenden Absichten der Reaktion, das Wahlrecht anzutasten" tue die Erwägung aller Mittel, die in einem solchen Fall anwendbar seien, dringend Not; Schwäbische Tagwacht Nr. 181 vom 5. 8. 1904. S. 5. Zetkins Beitrag wurde von den Anwesenden mit lebhaftem Beifall quittiert.

${ }^{31}$ Vgl. Franz Osterroth und Dieter Schuster: Chronik der deutschen Sozialdemokratie. Bis zum Ende des Ersten Weltkrieges. Bd. 1. ${ }^{21975}$. S. 119. - Punkt 6 der Tagesordnung „Der politische Massenstreik und die Sozialdemokratie“; vgl. „Parteitag der Sozialdemokratischen Partei Deutschlands“, Schwäbische Tagwacht Nr. 218 vom 19. 9. 1905. S. 5.

32 Vgl. Sozialistenkongress (wie Anm. 25) S. 24.

33 Vgl. „Unser Parteitag“, Schwäbische Tagwacht Nr. 216 vom 16. 9. 1905. S.1. - Diese Aussage muss der Meinung der „Tagwacht“-Redaktion entsprochen haben, die damals noch unter der Leitung Wilhelm Keils stand.

34 „Parteitag der Sozialdemokratischen Partei Deutschlands“, Schwäbische Tagwacht Nr. 222 vom 23. 9. 1905. S. 9. - Protokoll über die Verhandlungen des Parteitages der Sozialdemokratischen Partei Deutschlands. Abgehalten zu Jena vom 17. bis 23. September 1905. 1905. S. 129.

35 Vgl. Protokoll (wie Anm. 34) S. 323.

36 Sie gruppierten sich um äußerst gemäßigt eingestellte Kräfte, wie die Reichstagsabgeordneten Theodor Bömelburg, Wolfgang Heine, Carl Legien und Robert Schmidt; vgl. Protokoll (wie Anm. 34) S. 343.

37 Dahingehend äußerte sich z.B. der Delegierte Heine; vgl. Protokoll (wie Anm. 34) S. 316 . 
wehren, sondern auch um „sich ein wichtiges Grundrecht für ihre Befreiung zu erobern" 38 .

Sowohl vor als auch nach dem Parteitag sprachen sich laut den Berichten der Schwäbischen Tagwacht verschiedene städtische Vereine Württembergs für den Massenstreik aus ${ }^{39}$. Die Anerkennung des Massenstreiks als zusätzliches „Kampfmittel“ scheint demnach sowohl in der reichsweiten als auch in der württembergischen Sozialdemokratie kaum umstritten gewesen zu sein ${ }^{40}$. Mit Sicherheit war die zum Teil euphorische Zustimmung auch vom Beginn der Revolution in Russland geprägt $\mathrm{t}^{41}$.

\section{Die Anwendung des Massenstreiks rückt in weite Ferne}

Kurz nach dem Jenaer Kongress radikalisierte sich in Sachsen die Wahlrechtsbewegung und weitete sich aus bis nach Hamburg, Braunschweig, Hessen, Preußen und in das Elsass ${ }^{42}$. Dies rückte die Massenstreikdebatte nun in ein neues Licht. Laut Jenaer Beschluss wäre die Anwendung des Massenstreik "gegebenen Falles“ ein wirksames Kampfmittel. Rückte dieser Fall nun näher?

In der Mitgliedschaft dominierten nun drei Meinungen. Die einen lehnten den Massenstreik weiterhin grundsätzlich ab und verurteilten die Resolution von Jena; so äußerten Heymann und Hildenbrand „die Parteileitung [sei] den anarcho-syn-

38 Protokoll (wie Anm.34) S.142f. (Resolution Bebel „Der politische Massenstreik und die Sozialdemokratie“). - Die Abstimmung erfolge mit 287 Fürstimmen, 14 Gegenstimmen und zwei Enthaltungen; vgl. ebd. S. 342.

39 So etwa auf den Monatsversammlungen der Vereine Obertürkheim am 9. September 1905 und Esslingen am 10. September 1905; vgl. „Aus der Partei“, Schwäbische Tagwacht Nr. 213 vom 13. 9. 1905. S. 5. - Nach dem Parteitag sprachen sich die Versammlungen in Heslach, Feuerbach und Heilbronn für die Beschlüsse von Jena hinsichtlich der Massenstreikfrage aus; vgl. „Aus der Partei“, Tagwacht Nr. 240 vom 14.10. 1905. S. 6. sowie „Aus der Partei“, Tagwacht Nr. 242 vom 17. 10. 1905. S. 6. ferner „Aus der Partei“, Tagwacht Nr. 234 vom 7. 10. 1904. S. 10.

${ }^{40} \mathrm{Da}$ das Landesorgan stets über Kontroversen berichtete, ist davon auszugehen, dass es zumindest eine kurze Notiz darüber gegeben hätte, wenn einzelne Vereine sich gegen den Massenstreik ausgesprochen hätten.

${ }^{41}$ Die Schwäbische Tagwacht unterrichtete die württembergische Mitgliedschaft ausführlich über die Vorgänge in Russland. Zum Beginn der Revolution vgl. auszugsweise „Russland vor der Revolution“, Schwäbische Tagwacht Nr.17 vom 21.1. 1905. S. 2. - „Die Bluttaufe der russischen Revolution“, Tagwacht Nr. 18 vom 23.1. 1905. S.1. - „Russische Schicksalstage“, Tagwacht Nr. 19 vom 24.1. 1905. S. 1. - „Der Bürgerkrieg in Russland“, Tagwacht Nr. 20 vom 25.1. 1905, S. 1-2. - Später erschien auf Seite 2 bzw. 3 eine eigene Rubrik „Die Vorgänge in Russland“, die fast täglich aus Russland berichtete: Vgl. auszugsweise „Die Vorgänge in Russland“, Tagwacht Nr. 209 vom 8. 9. 1905. S.3. - Sowie „Die Vorgänge in Russland“, Tagwacht Nr. 213 vom 13.9. 1905. S.2.

${ }^{42}$ Vgl. Schorske (wie Anm. 27) S. 73. 
dikalistischen Einflüssen unterlegen“43. Befürworter des Massenstreiks waren zwar nicht für eine unmittelbare Propagierung ${ }^{44}$, bekräftigten aber, man müsse beginnen darauf hinzuarbeiten. So erklärte die Monatsversammlung des Bezirks Cannstatt, „daß die Diskussion über den politischen Massenstreik eine unbedingte Notwendigkeit ist, damit, falls einmal zu diesem Mittel gegriffen werden müsste, die Massen nicht unvorbereitet sind “45. Eine dritte Meinung äußerte Wilhelm Keil. Laut Keil käme der Massenstreik in Süddeutschland höchstens bei einer versuchten Beschneidung des Reichstagswahlrechts in Frage; schließlich sei hier - anders als in Preußen und Sachsen - das Dreiklassenwahlrecht schon abgeschafft worden ${ }^{46}$. Diese deutliche Abgrenzung von der politischen Lage in Norddeutschland, die hier erstmals überliefert ist, wurde zu einer Grundhaltung der süddeutschen Reformisten. Radikalere Forderungen sollten demnach vielleicht in Norddeutschland angemessen sein, nicht jedoch im „liberalen“ Süddeutschland.

Auf dem Mannheimer Parteitag im September 1906 verabschiedete die Reichspartei eine Resolution, die ein „Meilenstein in der Geschichte der deutschen Sozialdemokratie ${ }^{\text {47 }}$ war. Der Jenaer Beschluss wurde zwar bestätigt, doch neu war nun folgende Prämisse: „Sobald der Parteivorstand die Notwendigkeit eines politischen Massenstreiks für gegeben erachtet, hat derselbe sich mit der Generalkommission der Gewerkschaften in Verbindung zu setzen [...] Beide Organisationen sind [...] in ihren Kämpfen auf gegenseitige Verständigung und Zusammenwirken angewiesen. ${ }^{* 48}$

Im Klartext hieß das: Ohne das Einverständnis der Gewerkschaften würde die Partei nicht zum Streik aufrufen. Laut der Schwäbischen Tagwacht feierte die bürgerliche Presse, „daß auf dem Mannheimer Parteitag die ,radikale Richtung von den ,gewerkschaftlich-revisionistischen Reformern' zurückgedrängt worden sei“49. Allerdings, hieß es weiter, habe sich am Standpunkt der Sozialdemokratie nichts Wesentliches geändert, man habe lediglich die vorhandenen Gegensätze zwischen Partei und Gewerkschaft ausgeglichen und die Partei im Ganzen erheblich gestärkt ${ }^{50}$.

43 „Aus der Partei“, Schwäbische Tagwacht Nr. 196 vom 24. 8. 1906. S. 6.

${ }^{44}$ So die Wortmeldungen auf einer Stuttgarter Parteiversammlung: Georg Reichel etwa sagte, der Massenstreik könne für die Zukunft gegebenenfalls zur Anwendung kommen, seine Propagierung sei jetzt jedoch zwecklos; "Aus der Partei“, Schwäbische Tagwacht Nr. 196 vom 24. 8. 1906. S. 6.

45 „Aus der Partei“, Schwäbische Tagwacht Nr. 213 vom 24. 9. 1906. S. 6.

46 "Aus der Partei“, Schwäbische Tagwacht Nr. 196 vom 24. 8. 1906. S. 6.

47 Schorske (wie Anm. 27) S. 78.

48 Protokoll über die Verhandlungen des Parteitages der Sozialdemokratischen Partei Deutschlands. Abgehalten zu Mannheim vom 23. bis 29. September 1906. 1906. S. 473.

49 „Lehren des Mannheimer Parteitags“, Schwäbische Tagwacht Nr. 233 vom 6. 10. 1906. S.1.

50 „Lehren des Mannheimer Parteitags“, Schwäbische Tagwacht Nr.233 vom 6. 10. 1906. S. 1. - Tatsächlich revidierte die Partei den Jenaer Beschluss nicht formell, wohl aber faktisch. Der Gewerkschaftskongress von 1905 hatte den Massenstreik abgelehnt und zu einem Kon- 
In den frühen Massenstreikdebatten ist die Haltung Wilhelm Keils bemerkenswert. Prinzipiell sprach er sich nie gegen den Massenstreik aus und unterschied sich hierbei von den gemäßigteren Mitgliedern. Sobald die Prinzipienfrage aber „konkreter" wurde und damit eine mögliche Umsetzung näher rückte, distanzierte er sich ausdrücklich von den radikaleren Kräften. Anfangs mit der Begründung eine intensivere Diskussion sei (noch) nicht notwendig, 1906 dann mit dem Argument, ein Massenstreik in Süddeutschland sei aufgrund des hiesigen Wahlrechts obsolet. Dass ein Streik - gemäß dem Jenaer Beschluss - ein Mittel sein könnte „ein wichtiges Grundrecht zu erobern“, das auch ein anderes sein könne als das Wahlrecht, schien Keil, zumindest für Württemberg, überhaupt nicht in Erwägung zu ziehen.

\section{Die Bewilligung des Landesetats durch die württembergische Landtagsfraktion 1907}

Die Diskussion über die „Budgetbewilligung“ begann im Jahr 1907, als die württembergische Landtagsfraktion am 27. Juli erstmals dem Landesetat zustimmte ${ }^{51}$. Der Protest der Parteigenossen ließ nicht lange auf sich warten, sollte doch durch die Ablehnung des Budgets „der grundsätzliche Gegensatz zum Ausdruck gebracht werden, in dem sich die Arbeiterklasse gegenüber dem kapitalistischen Klassenstaate und seiner Regierung befindet ${ }^{\star 52}$. Dies war zumindest die verbreitete Auffassung seit dem Lübecker Parteitag von 1901 und der dort verabschiedeten Resolution. Diese sprach die Erwartung aus, „dass die sozialdemokratischen Vertreter in den gesetzgebenden Körperschaften der Einzelstaaten [...] insbesondere das Gesamtbudget normalerweise ablehnen ${ }^{\text {“533. }}$.

flikt zwischen Partei- und Gewerkschaftsführung geführt. Der Mannheimer Beschluss, mit dem sich die „Tagwacht“-Redaktion äußerst zufrieden zeigte, räumte nun den rechteren Gewerkschaftsführungen ein Veto-Recht ein und erschwerte dadurch eine mögliche Anwendung des Massenstreiks. Zugleich wurde dadurch der Konflikt zwischen Partei und Gewerkschaften beigelegt; vgl. Schorske (wie Anm. 27) S. 78f. - Über den genauen Verlauf des Konflikts und das Verhältnis zwischen Partei und Gewerkschaften vgl. Joachim Eichler: Von Köln nach Mannheim. Die Debatten über Maifeier, Massenstreik und das Verhältnis der Freien Gewerkschaften zur deutschen Sozialdemokratie innerhalb der Arbeiterbewegung Deutschlands 1905/06. 1988.

51 Otto Wasner und Karl Kloß waren bei der Abstimmung nicht anwesend; vgl. „Schlussabstimmung [...] des Hauptfinanzetats für die Rechnungsjahre 1907 und 1908“. In: Verhandlungen der württembergischen Zweiten Kammer (Kammer der Abgeordneten) auf dem 37. Landtag im Jahre 1907. Protokollband 85. 1907. S. 1753. - Vgl. ferner Christ-Gmelin (wie Anm. 6) S. 146.

52 So die Äußerung des Reichstagsabgeordneten Wurm auf dem Parteitag von 1901, zitiert nach Wilhelm Schröder: Handbuch der sozialdemokratischen Parteitage: 1863-1909. Bd.1. 1910. S. 102.

${ }^{53}$ Protokoll über die Verhandlungen des Parteitages der Sozialdemokratischen Partei 
Zum Streitpunkt wurde nun die Frage, ob die erfolgte Bewilligung im Widerspruch mit der Lübecker Resolution stand, die nämlich einen Ausnahmefall einräumte: „Eine Zustimmung zu dem Budget kann nur ausnahmsweise aus zwingenden, in besonderen Verhältnissen liegenden Gründen gegeben werden. “54 Das ausschlaggebende Motiv, das 1907 zur Befürwortung des württembergischen Etats geführt habe, beschrieb Wilhelm Keil rückblickend wie folgt: „Die Fraktion wurde sich zunächst rasch einig, dass sie, wie in früheren Jahren [...] mit Nein stimmen werde. [...] Da fielen nun gerade in diese Tage die Besprechungen [...] über den dicht bevorstehenden internationalen Sozialistenkongress [...] Der Minister [Pischek, die Verf.] verhielt sich entgegenkommend, und der Kongress [...] schien gesichert zu sein. Mir wurden vertraulich Andeutungen gemacht, daß es jetzt nicht ratsam sei, bei der Etatsabstimmung mit einem Nein gegen die Regierung zu demonstrieren. Ich hatte Verständnis dafür. [...] Könnte es nicht, wenn wir jetzt die Regierung reizten, nachteilige Folgen für den Verlauf des Kongresses haben? Mit dieser Erwägung trat ich an die Fraktion heran und nach wenigen Minuten war beschlossen, diesmal für den Etat zu stimmen ohne besondere Motivierung. So geschah es. “55

Nach Bekanntwerden der Budgetbewilligung erfolgten in Stuttgart in den Bezirksversammlungen Heslach und West kontroverse Diskussionen über das Verhalten der Abgeordneten ${ }^{56}$. Auf der Stuttgarter Parteiversammlung vom 9. September rechtfertigten die Fraktionsmitglieder die Budgetbewilligung. Bezeichnenderweise sprachen sich, anders als Keil, die Abgeordneten Hildenbrand, Heymann und Fischer im Grunde für eine neue Taktik aus. Demnach sollte die Budgetverweigerung nicht als Prinzipienfrage betrachtet werden (die die prinzipielle Ablehnung des kapitalistischen Staates zum Ausdruck brachte), sondern als Taktikfrage, die von Fall zu Fall neu entschieden werden müsse ${ }^{57}$.

Laut Hildenbrand, sei der [Sozialisten-, die Verf.] Kongress nicht der einzige Grund, sondern „nur einer der Gründe“ gewesen, der zur Etatbewilligung geführt habe. Man war der Meinung, dass es nicht möglich sei, auf der einen Seite für einen

Deutschlands. Abgehalten zu Lübeck vom 23. bis 28. September 1901. S. 99. Bestärkt und verschärft wurde dieser Beschluss zwei Jahre später durch die Dresdner Resolution von 1903.

${ }^{54}$ Protokoll (wie Anm. 53) S. 99. - Zur Abstimmung vgl. ebd. S. 284.

${ }^{55}$ Keil (wie Anm. 12) S. 240.

${ }^{56}$ In Heslach verteidigten die Mitglieder Tarnow und Bauzhaf die Budgetbewilligung, während Westmeyer, Lehmann und Dörffer der Meinung waren, „daß die Gründe, die für die Abstimmung der Fraktion bis jetzt benannt worden seien, als durchschlagend nicht anerkannt werden könnten“; Schwäbische Tagwacht Nr. 186 vom 12.8. 1907. S. 3. - Im Bezirk West kritisierten Schlür, Waldmann und Behr die Haltung der Fraktion. Der Landtagsabgeordnete Fischer bezog kurz Stellung zur Etatabstimmung und rechtfertigte diese, verwies jedoch auf die Landesversammlung, die kompetent sei, in dieser Frage zu entscheiden. Seinen Standpunkt unterstützten „einige weitere Redner“; Tagwacht Nr. 186 vom 12. 8. 1907. S.3.

${ }^{57}$ Vgl. Die Beiträge von Hildenbrand und Heymann in: Schwäbische Tagwacht Nr. 211 vom 10. 9. 1907. S. 6 f. - Sowie die Beiträge Fischer, Heymann und Hildenbrand in: Tagwacht Nr. 215 vom 14. 9. 1907. S. 9 f. 
bestmöglichen Etat zu streiten (etwa in Form von Änderungsanträgen) und auf der anderen Seite denselben Etat, den man verbessert habe, als „Spiegelbild ungerechter Gesellschaftsverhältnisse“ prinzipiell abzulehnen. Hildenbrand erklärte, die Fraktion habe nach wochenlangen Kämpfen im Landtag die verschiedensten Zugeständnisse erzwungen ${ }^{58}$. Hätte sie dem Budget nicht zugestimmt, so hätte ihr entgegengehalten werden können: „Erst verlangt ihr alles Schöne, und nachher bewilligt ihr die Mittel nicht! " ${ }^{59}$ Ein normales württembergisches Gehirn, polemisierte er, hätte eine Ablehnung des Etats nicht begreifen können. In den Vorjahren habe dies in den Reihen der Arbeiterschaft auf dem Land bereits verwirrend und hindernd gewirkt.

Darüber hinaus, so Hildenbrand weiter, sei die Stellung der württembergischen Regierung zur Sozialdemokratie doch ganz anders als z.B. in Preußen und Sachsen. Kein Wort für die Budgetabstimmung wäre gefallen, wenn preußische Zustände herrschen würden ${ }^{60}$. Wie schon zuvor in der Massenstreikfrage wurden die besonderen württembergischen Verhältnisse als Rechtfertigung angeführt. Schließlich forderte Heymann, den Abgeordneten Vertrauen entgegenzubringen und „keine gebundene Marschroute“ auf den Weg zu geben. „Man lasse der Fraktion soviel Freiheit, aus eigener Kraft, aus eigener Fähigkeit ihre Beschlüsse zu fassen.“61

Diese Haltung führte zu großer Erregung in der Versammlung, da die Infragestellung einer prinzipiellen Budgetablehnung im Widerspruch zu den Lübecker Beschlüssen stand. Behr, der die Etatbewilligung als einen „recht dummen Streich “62 der Fraktion kritisierte, sagte, die Gründe für die bisherige Ablehnung des Etats treffen weiterhin zu. Diese Gründe seien auch von dem normalen Hirn der württembergischen Wähler sehr gut begriffen worden, so Behr. Nach den drei verneinenden Etatabstimmungen von 1901, 1903 und 1905 sei die Stimmenzahl der Sozialdemokratie von 58.000 auf 91.000 gestiegen. Die Bevölkerung habe also die Haltung sehr wohl verstanden. Der Regierung Vertrauen entgegenzubringen, ihr Entgegenkommen zu zeigen, das sei Sache derjenigen, deren Interessen die Regierung vertrete, deren Geschäfte sie besorge. Die Sozialdemokratie aber, die von der Regierung bekämpft und verfolgt werde, dürfe ihr nur mit dem schärfsten Misstrauen begegnen.

Roßmann warf der Fraktion vor, mit den Prinzipien der Partei zu brechen: „Zu den Ausnahmen, welche die [Lübecker, die Verf.] Resolution zulässt, gehören alle

${ }^{58}$ Hildenbrand spielte damit vor allem auf die Beamtenvorlage an, die insbesondere für die unteren Beamten Verbesserungen einführte; vgl. Protokoll der Landesversammlung. In: Bericht des Landesvorstandes der Sozialdemokraten Württembergs an die Landesversammlung 1907. O.J. [1907]. S. 99.

59 Schwäbische Tagwacht Nr. 211 vom 10.9. 1907. S. 6 f.

60 Schwäbische Tagwacht Nr. 211 vom 10.9. 1907. S.6f.

61 Schwäbische Tagwacht Nr. 215 vom 14. 9. 1907. S. 10.

62 Schwäbische Tagwacht Nr. 211 vom 10.9. 1907. S.7. 
die Gründe nicht, die wir hier gehört haben. [...] Kein Fraktionsmitglied hat erklärt, daß es sich nur um einen Ausnahmefall handelt, es ging vielmehr aus Heymanns Rede hervor, daß damit eine prinzipielle Schwenkung beabsichtig war. (Sehr richtig!).“63

Auch Westmeyer sprach von einer „grundsätzlichen Schwenkung “64 der Fraktion. Die Haltung der Fraktion, so Westmeyer, unterscheide sich in nichts von der anderer Parteien, die auch nicht mit allen Einzelheiten des Etats einverstanden seien.

Schlussendlich äußerte Keil einen anderen Standpunkt als seine Fraktionskollegen: „Ich geniere mich nicht, vor dieser Versammlung offen zu erklären, daß für mich der Internationale Kongreß allein ausschlaggebend gewesen ist."65 „Das ist opportunistisch“, warf ihm in einem Zwischenruf Heymann vor. Es habe sich, so Keil, bei der Abstimmung darum gehandelt, keine Provokationen herbeizuführen um ein mögliches Verbot des Kongresses zu vermeiden. Gewiss seien für die Gesamtfraktion auch noch andere Gründe maßgebend gewesen. Doch er, Keil, sei nicht der Meinung, dass man seine Tätigkeit bei den Einzeletats verleugne, wenn man zum Schluss gegen den Etat stimme. „Wir haben diesen gegnerischen Einwand seither pariert und das wird auch künftig möglich sein“66, fügte er hinzu.

Vermutlich erreichte es Keil durch seine Rede, die erhitzten Gemüter zu beruhigen und verhinderte dadurch, dass der Fraktion ein Misstrauensvotum ausgesprochen wurde ${ }^{67}$. Auch die Landesversammlung knapp einen Monat später sah von einem Misstrauensvotum ab. Der Abgeordnete Lindemann verwies auf die rein taktische Bedeutung der Bewilligung. Auch er betonte, die Fraktion sei für „eine Reihe wichtiger Verbesserungen der Gehalts- und Lohnverhältnisse der Beamten und auch der Staatsarbeiter“ im Etat „außerordentlich eifrig“ tätig gewesen; die Arbeiterschaft hätte nicht verstanden, wenn die Fraktion „in der Gesamtabstimmung ihr Werk wieder zerstörte ${ }^{\text {“68 }}$. Außerdem habe „die vorurteilsfreie Haltung“ der württembergischen Regierung dem Internationalen Kongress gegenüber „kei-

${ }^{63}$ Schwäbische Tagwacht Nr. 215 vom 14. 9. 1907. S. 9.

${ }^{64}$ Schwäbische Tagwacht Nr. 215 vom 14. 9. 1907. S. 10.

${ }^{65}$ Schwäbische Tagwacht Nr. 215 vom 14. 9. 1907. S. 9.

${ }^{66}$ Schwäbische Tagwacht Nr. 215 vom 14. 9. 1907. S. 9.

67 Diese Ansicht vertrat Keil selbst in seinen Memoiren: „Mit der Geltendmachung meiner Gründe, die die allgemeine Taktik unberührt ließen und die diesmalige Budgetgenehmigung als den Ausnahmefall kennzeichnete, erreichte ich die Ablehnung des Misstrauensvotums"; Keil (wie Anm.12) S.241. Der Verlauf der Parteiversammlung wie er in der Schwäbischen Tagwacht geschildert wird, lässt darauf schließen, dass Keils Wirken die polarisierte Stimmung tatsächlich beruhigte. - Kurz nach der Rede Keils ging ein Antrag ein, der die Budgetabstimmung billigte. Insgesamt lagen der Versammlung am Ende fünf Resolutionen vor, von denen sich zwei entschieden gegen die Bewilligung aussprachen. Mit 169 zu 59 Stimmen beschloss die Mitgliedschaft jedoch, keine der Resolutionen zur Abstimmung zu stellen; vgl. Schwäbische Tagwacht Nr. 215 vom 14. 9. 1907. S. 9.

68 Protokoll (wie Anm. 58). S. 99. 
nen Anlass [gegeben], dieser Regierung gerade jetzt ein besonders scharfes Misstrauensvotum auszusprechen" 69 .

Kanser entgegnete, man müsse entschieden ablehnen, den Abgeordneten freie Hand zu lassen. „Wer sich nicht an die Beschlüsse der Partei halten will, soll sich nicht in den Landtag schicken lassen “70, reklamierte er und erinnerte an den Lübecker Beschluss. Er legte eine Resolution vor, die der Fraktion ein klares Misstrauensvotum aussprach: „Die Landesversammlung bedauert [...], daß die sozialdemokratische Landtagsfraktion bei der Schlussabstimmung über den Gesamtetat diesem ihre Zustimmung gegeben hat. Die Vertreter der Arbeiter im Parlament haben die Pflicht [...] die unversöhnliche Gegnerschaft der Sozialdemokratie gegen den Klassenstaat zum Ausdruck zu bringen. Die Zustimmung zum Budget ist aber eine Vertrauenskundgebung für die Regierung und damit eine Anerkennung des Klassenstaats. Die Landesversammlung erwartet, daß die sozialdemokratische Fraktion des Landtags künftighin in Übereinstimmung mit dem Beschluss des Lübecker Parteitags zu einer Ablehnung des Gesamtetats kommt.“71

Für die Resolution Kansers sprachen sich die Delegierten Schäfer, Zetkin, Kinkel und Kopp aus ${ }^{72}$. Der einzige im Protokoll nachgewiesene Redner, der die Budgetbewilligung verteidigte, war der Delegierte Keck aus Sulz. Als Delegierter einer Kleinstadt betonte er, dass „die ländlichen Delegierten [...] betreffs der Budgetabstimmung anderer Meinung [seien] als die Genossen in den größeren Städten “73. So sagten diese, es sei kein Schaden, dass die Fraktion dem Etat im Ganzen zugestimmt habe, denn die bäuerliche Bevölkerung und die Arbeiterschaft in den kleineren Orten hätten eine Ablehnung seitens der Fraktion nicht verstehen können. „Wir sind also mit der Tätigkeit unserer Fraktion und mit der Abstimmung zum Etat einverstanden“"74, erklärte Keck. Er legte eine Resolution vor, die lediglich das Fehlen einer ausführlichen Begründung monierte ${ }^{75}$.

Trotz der erregten Diskussion, wurden bei der Schlussabstimmung beide Resolutionen abgelehnt ${ }^{76}$. Zwar gab es in der württembergischen Partei energischen Protest gegen die Etatbewilligung, die Mehrheit der Mitgliedschaft war aber nicht bereit, der Landtagsfraktion ein Misstrauensvotum auszusprechen. Das Vertrauen in die Tätigkeit der Landtagsfraktion und die Loyalität ihr gegenüber waren offenbar zu diesem Zeitpunkt noch sehr groß. Zudem räumte der Lübecker Beschluss

69 Protokoll (wie Anm. 58) S. 99.

70 Protokoll (wie Anm. 58) S. 102.

71 Protokoll (wie Anm. 58) S. 100 f.

72 Protokoll (wie Anm. 58) S. 102 ff.

73 Protokoll (wie Anm. 58) S. 102.

74 Protokoll (wie Anm. 58) S. 102.

75 „Die Versammlung“, heißt es da, „hätte [...] gewünscht, daß die Zustimmung zum Etat mit einer entsprechenden Begründung versehen gewesen wäre“; Protokoll (wie Anm. 58) S. 101.

${ }^{76}$ Keil schrieb später, dass „einige unentwegte Prinzipienreiter [...] der Fraktion ein Misstrauensvotum ausstellen [wollten]“; Keil (wie Anm.12) S. 241. 
tatsächlich Ausnahmefälle ein, und Wilhelm Keil konnte mit Verweis auf den Sozialistenkongress einen Teil der Mitgliedschaft davon abhalten, in der Budgetbewilligung einen Prinzipienbruch und eine grundsätzliche Änderung der Taktik zu sehen. Dennoch wurden die Meinungsverschiedenheiten konsequent ausgefochten und führten zu einer gewissen Polarisierung, insbesondere zwischen Hildenbrand, Heymann, Fischer und Lindemann auf der einen Seite und Westmeyer und Zetkin auf der anderen Seite.

Die Debatte auf der Landesversammlung zeigte auch Meinungsunterschiede zwischen Mitgliedern städtischer und ländlicher Ortsvereine. Immerhin waren alle Redner, die sich dem Protokoll nach gegen die Budgetbewilligung wandten, Vertreter städtischer Ortsvereine, und zwar aus Stuttgart (Schäfer, Zetkin, Kanser, Westmeyer), Göppingen (Kopp) und Gmünd (Kinkel) ${ }^{77}$. Mit Ausnahme der Landtagsabgeordneten war der Delegierte Keck aus Sulz hingegen der einzige Redner, der die Etatbewilligung nicht beanstandete. Es ist davon auszugehen, dass er die Haltung seines Ortsvereins repräsentierte (zumal er auch eine Resolution vorlegte); vielleicht vertrat er auch die mehrheitliche Meinung ländlicher Delegierter, wie er selbst in seinem Redebeitrag zu verstehen gab.

Dies wäre eine weitere Erklärung für das Abstimmungsergebnis der Landesversammlung. Der Delegiertenschlüssel der württembergischen Partei favorisierte nämlich mitgliederschwache Ortsvereine ländlicher Gemeinden, die im Verhältnis zu den mitgliederstarken, städtischen Vereinen auf den Landesversammlungen stimmenmäßig überrepräsentiert waren ${ }^{78}$. Es ist deshalb nicht auszuschließen, dass das Ergebnis der Landesversammlung (das von einem Misstrauensvotum absah) weniger die mehrheitliche Meinung der württembergischen Gesamtmitgliedschaft verkörperte, als die geteilten Meinungen zwischen Delegierten städtischer und ländlicher Gemeinden.

Interessant ist ferner die Uneinigkeit einzelner Fraktionsmitglieder mit Wilhelm Keil, der abermals betonte, keineswegs eine neue Taktik wie Hildenbrand und Heymann zu befürworten. Ob dies tatsächlich seiner Meinung entsprach, oder ob er den Konflikt nur möglichst schnell beilegen wollte ${ }^{79}$, bleibt offen. Vielleicht er-

77 Vgl. Protokoll (wie Anm. 58) S. 102 ff.

78 Vgl. Henicke (wie Anm. 9) S. 67 und Christ-Gmelin (wie Anm.6) S. 196. - Die Radikalen versuchten mehrmals ohne Erfolg das Delegationssystem zu ändern; vgl. ebd. S. $196 \mathrm{f}$.

79 Vielleicht wollte Keil verhindern, dass die Angelegenheit auf dem anstehenden Parteitags zu Essen thematisiert werde. Tatsächlich fragte dort der Göppinger Delegierte Kinkel: „Die württembergische Regierung hat genau so wie alle anderen Regierungen alles gegen uns aufgeboten. War es da angebracht, ihr ein Vertrauensvotum zu erteilen, wie es die sozialdemokratische Landtagsfraktion durch Zustimmung zum Etat getan hat? [...] Ich möchte den Parteitag fragen, ob die Verhältnisse in Württemberg so waren, wie sie der letzte Absatz der Lübecker Resolution im Auge hat." Protokoll über die Verhandlungen des Parteitages der Sozialdemokratischen Partei Deutschlands. Abgehalten zu Essen vom 15. bis 21. September 1907. 1907. S. 330. - Auf Kinkels Frage wurde nicht eingegangen. 
kannte er, dass die Mitglieder einen taktischen Umschwung nicht tolerieren würden und fand im Sozialistenkongress die willkommene Ausflucht.

\section{Budgetbewilligung in Baden und Bayern - die Süddeutschen Landtagsabgeordneten verabreden eine neue Taktik}

Ein Jahr später stellte sich die Situation deutlich anders dar. Mittlerweile hatten die Landtagsfraktionen in Bayern und Baden sowohl 1907 als auch 1908 erneut für den Landeshaushalt gestimmt ${ }^{80}$. Auf einer Versammlung im Frühjahr 1908 hatten die süddeutschen Landtagsabgeordneten - unter Ausschluss der restlichen Mitgliedschaft - vereinbart „,in der Regel in ihren Landesparlamenten für die Budgets zu stimmen “ ${ }^{\prime 1}$. Ohne die Mitsprache der anderen Mitglieder und entgegen den Parteitagsbeschlüssen verabredeten sie die Anwendung einer neuen Taktik.

Die badische Fraktion, die im Landtag für die Erhöhung der Beamtengehälter und Arbeiterlöhne gestritten hatte, rechtfertigte die Etatbewilligung von 1908 ähnlich wie die württembergischen Abgeordneten im Jahr zuvor: „Nachdem die sozialdemokratische Fraktion am Zustandekommen der Beamtengesetze nach besten Kräften mitgearbeitet hat, hält sie sich für verpflichtet, mitzuwirken bei der Beschaffung der Mittel, die zur Ausführung dieser Gesetze notwendig ist. Nur aus diesem Grund hat die Fraktion es unterlassen, ihr Misstrauen gegen die Regierung durch Ablehnung des Budgets zum Ausdruck zu bringen. “ 82

Auch die bayerische Fraktion begründete die Bewilligung mit einer Reihe von Verbesserungen, die das Budget umfasse und erklärte: „Wenn nun auch diese Aufwendungen in zahlreichen Einzelheiten selbstverständlich keineswegs genügen können, so erblicken wir noch in ihrer Gesamtheit einen Fortschritt und haben ihnen deshalb zugestimmt. “83

Auf der Stuttgarter Parteiversammlung vom 28. August folgte eine kontroverse Debatte. Laut Sitzungsprotokoll legte Heymann im Auftrag der Stuttgarter Abgeordneten folgende Ansicht dar: „Die Gesichtspunkte, von denen aus die badischen und bayerischen Genossen in diesem Jahre für das Budget stimmten, seien nahe verwandt mit denen, aus denen im vorigen Jahre die württembergische Fraktion

80 Baden hatte bereits 1891/92, 1893/94, 1895/96 und 1899/1900 dem Budget zugestimmt, Bayern bereits 1894; vgl. Christ-Gmelin (wie Anm. 6) S. 146.

${ }^{81}$ Dieter Groh: Negative Integration und revolutionärer Attentismus. Die deutsche Sozialdemokratie am Vorabend des Ersten Weltkrieges. 1973. S. 180.

82 „Die Budgetabstimmung der badischen Landtagsfraktion“, Schwäbische Tagwacht Nr. 187 vom 13. 8. 1908. S.1. Der Abstimmung blieben fern die Abgeordneten Geck, Lehmann und Eichhorn, der mittlerweile in Berlin lebte.

83 „Die Budgetabstimmung in Baden und Bayern“, Schwäbische Tagwacht Nr. 188 vom 14. 8. 1908. S. 2. Die Aufwendungen waren u. a. Kulturaufgaben, der Ausbau der Wasserkräfte, die Elektrifizierung von Eisenbahnstrecken und Beträge für die Aufbesserung der Arbeiter in Staatsbetrieben, der Lehrer und Beamten; vgl. ebd. S. 2. 
den Etat genehmigte. Unverständlich bleibe, warum man sich in diesem Jahre so riesig aufregt, während im vorigen Jahre die württembergische Abstimmung verhältnismäßig ruhig diskutiert wurde. [...] Er [Heymann, die Verf.] folgere daraus, daß diese Fragen nicht mehr nach sachlichen Gesichtspunkten entschieden würden, sondern daß man sich leiten lasse von leidenschaftlichem persönlichen Hass. (Heftiger Widerspruch.) [...] Man höre die Auffassung vertreten, daß wir mit der Etatverweigerung dem Klassenstaat das Fundament entziehen müssten; was mache es aber diesem Staate aus, wenn 15 unter 92 Abgeordneten ihm den Etat ablehnen. [...] Wir dürfen uns [...] nicht in ein Wolkenkuckucksheim begeben, sondern müssen auf dem Boden der Gegenwart bleiben. Wir können und wollen dem Klassenstaat nicht den Boden unter den Füßen wegziehen, sondern müssen darauf hinwirken, daß er sich allmählich zum sozialistischen Staat entwickelt. Wir müssen den kapitalistischen Staat befestigen, freilich nicht zugunsten der Kapitalisten, sondern in dem Sinne, daß wir ihm so viel als möglich Zugeständnisse abtrotzen. [...] Die Budgetfrage ist eine Frage der parlamentarischen Taktik. Wir sollten das Budget nur verweigern, wenn es sich um eine wichtige politische Aktion handelt. Wir sollten nicht zu oft demonstrieren. Arbeiten müssen wir. [...] Wer verlange, daß man unter allen Umständen den Etat ablehnen müsse, der entwerte den Parlamentarismus." ${ }^{\text {" } 84}$

Gegen Heymanns Beitrag sprachen sich Benz, Dr. Duncker, Kanser und Roßmann aus. Es gehe über seinen Verstand, so Duncker, die heutige Gesellschaft, wie Heymann sagte, zu befestigen ihr aber Zugeständnisse abzutrotzen. Die Folge einer derart revisionistischen Taktik wäre, dass an die Stelle einer Partei, die auf die möglichst rasche Umwandlung der bestehenden bürgerlichen in die sozialistische Gesellschaftsordnung hinarbeitet, also im besten Sinn des Wortes revolutionär sei, eine Partei trete, die sich mit der Reformierung der bürgerlichen Gesetze begnüge. Er betonte die symbolische Bedeutung einer Etatverweigerung: „Heymann erklärt, unsere Abstimmung ist nicht von entscheidender Bedeutung in den Landtagen; eben deshalb müssen wir die prinzipielle, die symbolische Bedeutung hervorheben. So gut wie der Einzelne sich zum Sozialismus bekennt, ohne damit sofort ihn verwirklichen zu können, sollen auch die Fraktionen zum Schluß bei der Budgetabstimmung sich zum Sozialismus bekennen, wenngleich damit der Klassenstaat nicht sofort beseitigt wird. “85

Auf einer zweiten Versammlung wurde die Debatte fortgeführt. Unter Zwischenrufen sprachen sich Brückner und Vorhölzer für die Etatbewilligung aus. Gegen Ende von Vorhölzers Rede heißt es im Protokoll: „Die Unruhe in der Versammlung steigert sich und die Schlussrufe werden immer häufiger. “86

84 „Parteiversammlung“, Schwäbische Tagwacht Nr. 201 vom 29. 8. 1908. S. 5.

85 "Parteiversammlung“, Schwäbische Tagwacht Nr. 201 vom 29. 8. 1908. S. 6.

86 "Parteiversammlung“, Schwäbische Tagwacht Nr. 203 vom 1. 9. 1908. S. 6 f. 
Clara Zetkins Beitrag wurde hingegen mit stürmisch anhaltendem Beifall entgegengenommen $^{87}$. In Anspielung auf die Absprache der Abgeordneten kritisierte sie, diese hätten sich auf den Standpunkt gestellt, dass die Masse der Parteigenossen nicht in der Lage sei, über die wichtigen Fragen der parlamentarischen Taktik mitzuentscheiden $^{88}$. Weiter wandte sich Zetkin gegen Heymanns Beitrag: „Heymann habe gesagt, man müsse den kapitalistischen Staat befestigen und verankern. [...] Diese Ansicht habe man schon mehr gehört, aber nicht von Sozialdemokraten, sondern von bürgerlichen Reformern. (Beifall.) Wir wollen freilich Reformen, so viel als irgend möglich, aber nicht um den bürgerlichen Staat zu erhalten, sondern um die Arbeiterklasse sittlich und wirtschaftlich zu heben, sie in den Stand zu setzten, den Kapitalismus zu zertrümmern. Auch die Gegner der Budgetbewilligung sind entschiedene Vertreter der Reformarbeit, aber dieselbe soll in enger Verbindung stehen mit unserem Endziel. Diese wird am sichersten verbürgt durch eine innige Verbindung der Berufsparlamentarier mit den Massen. “89

Anders als im Vorjahr verabschiedeten die Mitglieder mit großer Mehrheit eine Resolution, die die Budgetbewilligung verurteilte, den Bruch mit den Parteibeschlüssen von 1901 und 1903 sowie die „Tendenz, die Entscheidung über so wichtige Parteifragen [...] in das Dunkel kombinierter Fraktionssitzungen zu verlegen“. „Die Versammlung ist der Meinung“, hieß es weiter, „daß die ständige Zuspitzung der wirtschaftlichen und politischen Gegensätze auch in Süddeutschland eine Änderung der prinzipiellen Haltung der Partei nicht rechtfertigt.“90

Die Budgetbewilligung kritisierten auch die Generalversammlung des 3. württembergischen Reichstagswahlkreises ${ }^{91}$, die Parteiversammlung Tuttlingens ${ }^{92}$ sowie die Mitgliederversammlungen in Botnang ${ }^{93}$, Fellbach und Gmünd ${ }^{94}$. Gebilligt wurde das Verhalten der Abgeordneten in den Parteiversammlungen Schwenningen $^{95}$, Hall, Reutlingen, Ehingen, im Bezirksverein Vaihingen ${ }^{96}$ sowie in den Ortsvereinen $\mathrm{Ulm}^{97}$ und Nürtingen ${ }^{98}$. Die Mitgliederversammlung Kornwestheims

87 „Parteiversammlung“, Schwäbische Tagwacht Nr. 203 vom 1. 9. 1908. S. 7.

88 „Sie wollten als Pfarrerstöchter hübsch unter sich sein. [...] Die Masse hat [aber] in diesen allgemeinen Parteifragen mitzuentscheiden, auf den Massen allein beruht der Einfluss unserer Abgeordneten. Ohne die Masse sind sie trotz allen Fleißes, Geschicks und Talents nichts. Sie sollen nicht unter, aber in der Masse stehen.“ „Parteiversammlung“, Schwäbische Tagwacht Nr. 203 vom 1. 9. 1908. S. 7.

89 „Parteiversammlung“, Schwäbische Tagwacht Nr. 203 vom 1. 9. 1908. S. 7.

90 „Parteiversammlung“, Schwäbische Tagwacht Nr. 201 vom 29. 8. 1908. S. 5.

91 "Aus der Partei“, Schwäbische Tagwacht Nr. 203 vom 1. 9. 1908. S. 3.

92 „Aus der Partei“", Schwäbische Tagwacht Nr. 208 vom 7. 9. 1908. S. 3.

93 „Aus der Partei“", Schwäbische Tagwacht Nr. 211 vom 10. 9. 1908. S. 7.

94 „Aus der Partei“, Schwäbische Tagwacht Nr. 215 vom 15. 9. 1908. S. 3.

95 „Aus der Partei“, Schwäbische Tagwacht Nr. 210 vom 9. 9. 1908. S. 6.

96 „Aus der Partei“, Schwäbische Tagwacht Nr. 211 vom 10. 9. 1908. S. 7.

97 "Aus der Partei“", Schwäbische Tagwacht Nr. 213 vom 12. 9. 1908. S. 10.

98 „Aus der Partei“, Schwäbische Tagwacht Nr. 215 vom 15. 9. 1908. S. 3. 
sprach lediglich „die Hoffnung aus, dass der bevorstehende Parteitag diese Angelegenheit in einem für die Partei günstigen sinne [sic!] regeln werde ${ }^{\text {(999 }}$.

Der Nürnberger Parteitag, der sich mit der Budgetfrage beschäftigte, verabschiedete schließlich nach eingehender Debatte mit 258 zu 119 Stimmen die Resolution des Parteivorstands, die die Budgetbewilligung missbilligte ${ }^{100}$. Die Resolutionen von Lübeck und Dresden wurden bestätigt und die Budgetbewilligung in Württemberg, Baden und Bayern als unvereinbar mit jenen Beschlüssen erklärt ${ }^{101}$.

Die sieben anwesenden württembergischen Landtagsabgeordneten stimmten gegen die Resolution ${ }^{102}$. In der Debatte vertrat „den budgetfreundlichen Standpunkt der württembergischen Landtagsfraktion [...] Hildenbrand, den Standpunkt der württembergischen Budgetgegner Westmeyer" ${ }^{\text {"103. }}$. Hildebrand sprach im Namen der württembergischen Fraktion den anderen süddeutschen Fraktionen die „volle Solidarität“ aus und erklärte, dass es in Württemberg „zum großen Teil“104 dieselben Gründe waren, die zur Bewilligung des Budgets geführt hätten. Er erklärte die Resolution des Parteivorstandes für unannehmbar, da sie einen Beschluss beinhalte, der die Stellung der Fraktionen erschwere und Erfolge verhindere. Auf Seiten der Abgeordneten sei man überzeugt, dass versucht werde „uns in unserer Stellung, in unserer politischen Ehre zu kränken, und das sollten Sie nicht tun, im Interesse der Einigkeit, im Interesse der Geschlossenheit. (Lebhafter Beifall bei den Süddeutschen) “105.

Nach der Abstimmung reichten 66 süddeutsche Delegierte eine Erklärung ein, in der dem deutschen Parteitag „die oberste Entscheidung [...] in allen prinzipiellen und in den taktischen Angelegenheiten, die das ganze Reich berühren" zugestanden wurde. In „allen speziellen Angelegenheiten der Landespolitik“ sei jedoch die Landesorganisation die Instanz, um die Landespolitik ,nach den besonderen Verhältnissen selbständig zu bestimmen [...,] und die jeweilige Entscheidung über die Budgetabstimmung [... müsse] der Landtagsfraktion vorbehalten bleiben " ${ }^{\text {"106 }}$.

99 „Aus der Partei“, Schwäbische Tagwacht Nr. 210 vom 9. 9. 1908. S. 6.

100 Vgl. Protokoll über die Verhandlungen des Parteitages der Sozialdemokratischen Partei Deutschlands. Abgehalten zu Nürnberg vom 13. bis 19. September 1908. 1908. S. 424.

101 Laut Beschluss sei ,jeder gegnerischen Regierung das Staatsbudget bei der Gesamtabstimmung zu verweigern, es sei denn, daß die Ablehnung desselben durch unsere Genossen die Annahme eines für die Arbeiterklasse ungünstigeren Budgets zur Folge haben würde. [...] Die grundsätzliche Verweigerung des Budgets entspricht vollkommen der Klassenlage der besitzlosen Volksmassen, die eine unversöhnliche Opposition gegen die bestehende, dem Kapitalismus dienende Staatsgewalt notwendig macht. Die arbeitenden Klassen immer wieder nachdrücklich darüber aufzuklären, ist eine unerlässliche Aufgabe unserer agitatorischen Arbeit“; Protokoll (wie Anm. 100) S. 550.

102 Die sieben Abgeordneten waren: Feuerstein, Fischer, Heymann, Hildenbrand, Keil, Reichel und Schlegel; vgl. Protokoll (wie Anm. 100) S. 425.

103 Schröder (wie Anm. 52) S. 107 f.

104 Protokoll (wie Anm. 100) S. 326.

105 Protokoll (wie Anm. 100) S. 334.

106 Protokoll (wie Anm. 100) S. 426. 
Keil schrieb rückblickend: „Ich schloss mich dieser Gruppe [der Delegierten, die Verf.] an, obwohl ich mit den Ansichten ihrer Wortführer nicht voll übereinstimmte. Ich wollte zum Ausdruck bringen, daß ich als Abgeordneter mir persönlich das Recht vorbehielt, zu entscheiden, ob die Verhältnisse ein Ja oder ein Nein erforderten. “107

Auf der Landesversammlung vom 3. Oktober 1908 versuchten die Linken mittels einer Resolution die württembergischen Abgeordneten stärker an den Nürnberger Beschluss zu binden. In der von Kinkel eingereichten Resolution hieß es, dass sich die Landesversammlung mit den Beschlüssen des Nürnberger Parteitags einverstanden erklärte und „im Sinne dieser Beschlüsse für die Einheit der Partei“108 wirken würde. Keil verhinderte eine Abstimmung darüber, indem er äußerte: „Wir wissen worauf der Antrag abzielt. Wir können aber hier eine Budgetdebatte nicht mehr gebrauchen. (Lebhafte Zustimmung.) [...] So wenig wir in früheren Jahren zu den Parteitagsbeschlüssen noch einmal auf den Landesversammlungen Stellung genommen und ausgesprochen haben, ob wir einverstanden sind oder nicht, ebenso wenig brauchen wir es diesmal.“ ${ }^{109}$ Daraufhin zog Kinkel den Antrag zurück; auf Landesebene wurde erneut keine Stellungnahme zur Budgetbewilligung verabschiedet.

In Stuttgart hingegen war mittlerweile die Mehrheit der Mitgliedschaft der Auffassung, die süddeutschen Landtagsfraktionen verfolgten eine neue Taktik. Eine Änderung der bisherigen Taktik war man jedoch nicht bereit mitzutragen. Die Debatte in Stuttgart offenbarte Differenzen in Prinzipienfragen (s. die Beiträge von Heymann und Duncker): Die einen wollten den Staat erhalten und durch Reformen umgestalten, die anderen wollten ihn bekämpfen und durch einen neuen, sozialistischen ersetzen.

\section{Der „Hofgang“ der württembergischen Abgeordneten im Jahr 1909}

Am 22. Juli 1909 nahmen sieben Fraktionsmitglieder an einem Landtagsausflug der beiden württembergischen Kammern nach Friedrichshafen teil ${ }^{110}$. Dabei wurde der König in seiner Residenz besucht und im Schlossgarten ein Hoch auf ihn ausgebracht. Vor dem Hintergrund des Nürnberger Beschlusses und der Debatten von 1907 und 1908 erhitzten sich die Gemüter schnell, als die Angelegenheit auf der Stuttgarter Parteiversammlung behandelt wurde.

107 Keil (wie Anm. 12) S. 217.

108 Protokoll der Landesversammlung. In: Landesversammlung 1908. Bericht des Landesvorstandes, der Landtagsfraktion und Protokoll der Landesversammlung vom 3. und 4. Oktober in Stuttgart. O.J. [1908]. S. 168.

109 Protokoll (wie Anm. 108) S. 169.

110 Vgl. Schröder (wie Anm. 52) S. 336. 
In seiner Eröffnungsrede verurteilte Westmeyer das Verhalten der Abgeordneten. Das Betrübende und Erbitternde sei, so der Vorsitzende, dass diese die Fahrt freiwillig mitgemacht hätten, obgleich sie von den damit verbundenen monarchischen Huldigungen unterrichtet gewesen seien. Es handele sich hier nicht um die Person des Königs, sondern um die Monarchie als Institution des Klassenstaates, die die Sozialdemokratie programmgemäß mit aller Kraft bekämpfen müsse.

Unsinnig sei auch die Behauptung, die Fahrt habe keinen politischen Charakter getragen, sie sei eine rein gesellschaftliche Veranstaltung gewesen. Ein sozialdemokratischer Abgeordneter höre aber doch nicht auf, Sozialdemokrat zu sein. Nicht der Herr Buchhändler Fischer oder der Kaufmann Heymann, sondern der Landtag als politische Körperschaft sei geladen worden, als von der Sozialdemokratie gewählte Abgeordnete hätten die Betreffenden die Fahrt mitgemacht.

„Die ungeschulten Massen“, schlussfolgerte Westmeyer, „müssen irre werden an unserer Lehre, dass wir den Klassenstaat bekämpfen und stürzen wollen, sie müssen irre werden in ihrem Vertrauen zu ihren Vertrauensmännern, die sie ins Parlament entsandt haben, um dort den Klassenkampf zu führen. Darüber helfen die schönsten Parlamentsreden nicht hinweg. Sie finden keinen Glauben mehr. Das parlamentarische Kampfmittel wird entwertet, die Position, die wir in schweren Kämpfen unter großen Opfern errungen haben, in der Wertschätzung seitens der Parteigenossen herabgesetzt ${ }^{\text {" }}$ "11.

Anschließend verlas Westmeyer eine Resolution, die die Teilnahme am Hofgang als „Verstoß gegen die Grundsätze der Partei“ missbilligte ${ }^{112}$. Es folgte eine Stellungnahme Fischers, die laut Protokoll fast durchgehend von Gelächter und Zwischenrufen unterbrochen wurde. Der Besuch beim König war in den Augen der Mitgliedschaft offenbar eine absurde Vorstellung: „Er [Fischer, die Verf.] bestreite die Absicht, einen Parteikrakeel hervorzurufen, ganz entschieden. Es falle ihm auch heute nicht ein, einen Parteikrakeel heraufzubeschwören. (Zurufe: Das ist aber die Wirkung eueres Verhaltens!) Der Landtag veranstalte regelmäßig in gewissen Zeitabständen derartige Ausflüge. Es seien immer einige Genossen daran beteiligt gewesen. Wenn der Ausflug 3 Wochen vorher stattgefunden hätte, dann hätte er ohne den Besuch beim König stattgefunden. (Heiterkeit.) Es sei der Wunsch des Königs gewesen, daß ihn der Landtag besuche. (Lachen.) Der König habe den Landtag eingeladen. Nicht um eine Tafelung habe es sich gehandelt. Die Vorstellung sei eine ganz einfache gewesen. (Heiterkeit.) Von einer Huldigung vor der Monarchie könne keine Rede sein. (Widerspruch.) Die Beteiligung sei nur ein Ausdruck der Gleichberechtigung, die man verlange. (Stürmischer Widerspruch.) Es könne den Abgeordneten nicht verwehrt werden, sich an dem Ausflug zu beteiligen. (Erneut lebhafter Widerspruch.) Er verwahre sich dagegen, daß er vor der Monarchie einen Bückling gemacht haben solle. (Heiterkeit.) Bei den Hochrufen

111 „Parteiversammlung“, Schwäbische Tagwacht Nr. 187 vom 14. 8. 1909. S. 2.

112 „Parteiversammlung“, Schwäbische Tagwacht Nr. 187 vom 14. 8. 1909. S. 2. 
haben man sich durchaus passiv verhalten. (Lachen.) [...] Er glaube nicht, daß die Wähler in dem Vertrauen irre werden. (Lebhafter Widerspruch.) [...] Die Abgeordneten hätten keine Ursache, bei diesen Veranstaltungen zurückzustehen. Wenn man sich abschliesse, so könne man keine Vorteile erzielen. Die Abgeordneten nähmen für sich das Recht in Anspruch, überall dort zu sein, wo etwas los sei. (Großer Widerspruch.) Von diesem Standpunkt aus haben die Parteigenossen an dem Ausflug sich beteiligt und er meine, dazu seien sie berechtigt gewesen, auch wenn sie damit nichts erreicht hätten. (Allgemeine Heiterkeit.) [...] Er bestreite mit aller Entschiedenheit, gegen die Grundsätze der Partei verstoßen zu haben. Man spreche von Prinzipien. Er frage: Wo ist ein Prinzip? (Stürmisches Gelächter und Unterbrechungen.) [...] Die sieben Abgeordneten hätten mit ihrer Teilnahme gezeigt, dass sie vor Majestäten keine Angst haben. (Schallende Heiterkeit.) Er weise die Unterstellung Westmeyers zurück, als hätten die Abgeordneten sich etwas erbittet oder erschmeichelt. Die Abgeordneten hätten getan, was sie im Interesse der Partei und angesichts der bestehenden Situation für notwendig hielten. (Lebhafter Widerspruch.) Ob dabei etwas erreicht worden sei, sei eine Sache für sich. (Heiterkeit.) $)^{\text {113 }}$

In der Diskussion sprachen sich Roßmann, Hammer, Bratz, Schumacher, Brecht, Stetter, und Springer gegen den „Hofgang“ aus; nur der Abgeordnete Hildenbrand verteidigte diesen. Wenn Fischer, so Roßmann, die Erfolge der von ihm vertretenen Taktik zuschreibe, so sei die Heiterkeit, mit der die Versammlung dies quittiert habe, eine ausreichende Kritik dieser Ansicht. „Eine merkwürdige Auffassung habe Fischer von der ,Gleichberechtigung“ entwickelt“, so Roßmann: „Wo sei denn die Gleichberechtigung, wenn es sich um das Koalitionsrecht der Unterbeamten handle, wenn Staatsbeamte sich offen zur Sozialdemokratie bekennen! (Sehr richtig!) In Württemberg gehe die Gleichberechtigung nicht einmal soweit, daß das Aufhängen einer roten Fahne am 1. Mai geduldet werde. (Lebhafte Zustimmung.) Gesellschaftliche und politische Gleichberechtigung seien eben zwei ganz verschiedene Stiefel. (Sehr richtig!) [...] Ein sozialdemokratischer Abgeordneter habe nicht überall etwas zu suchen, wo etwas los sei. Er habe nirgends etwas verloren als da, wo Arbeiterinteressen zu vertreten seien. (Lebhafte Zustimmung.) Seien die Abgeordneten nicht in der Lage, die Frage, ob sie bei dieser Veranstaltung Arbeiterinteressen vertraten, mit ja zu beantworten, dann sei mit ihnen endlich ein ernstes Wort zu reden. (Lebhafter Beifall.) “114

Bratz erklärte sarkastisch: „Wenn vor 10 Jahren dem Genossen Tauscher einer gesagt hätte, er mache in 10 Jahren ein Gabelfrühstück beim König mit und führe den Klassenkampf mit Messer und Gabel (Heiterkeit), der hätte die zornige Antwort bekommen: Hebe dich hinweg von mir, Satan! (Große Heiterkeit!) Er rufe

113 „Parteiversammlung“, Schwäbische Tagwacht Nr. 187 vom 14. 8. 1909. S. 2.

114 „Parteiversammlung“", Schwäbische Tagwacht Nr. 187 vom 14. 8. 1909. S. 2 f. 
den Abgeordneten zu: Ihr seid allzumal Sünder, tuet Buße und bekehret euch. (Stürmische Heiterkeit.) “115

Als letzter Redner vor der Abstimmung erhielt Hildenbrand im Namen der Abgeordneten das Wort. „Die Genossen urteilen zu schnell“, beklagte er, „man dürfe die Abgeordneten nicht als Leute betrachten, die der Partei nur Schaden zufügen. [...] Es werde den Genossen zugemutet, zu beschliessen, die Teilnahme sei ein Verstoß gegen die Grundsätze der Partei gewesen. (Lebhafte Zustimmung.) Seien Sie doch nicht so ungerecht. Dem König sei bei seiner Einladung des Landtags so klar gewesen, dass er es mit den Sozialdemokraten mit überzeugten Republikanern zu tun habe (Lachen), wie mancher von den Genossen unklar über die Tragweite des heutigen Beschlusses. (Zuruf: Wir sind doch keine Esel!) [...] Die in Frage kommenden Parteigenossen seien der Meinung, dass sie die Grundsätze der Partei durch diese Beteiligung [am Königsbesuch, die Verf.] nach keiner Richtung verletzt haben. [...] Man müsse gerecht sein und die Fraktion nach ihrer Gesamttätigkeit, nicht nach einem Einzelfall beurteilen. (Beifall und Widerspruch.)“116

Doch die Abgeordneten blieben mit ihrem Standpunkt in der Minderheit; die Resolution wurde mit 195 gegen 74 Stimmen angenommen ${ }^{117}$. Die Stuttgarter Partei hatte mit überwältigender Mehrheit ein klares Zeichen gesetzt. Im Gegensatz dazu wurde auf der Generalversammlung des 6. Wahlkreises die Teilnahme der Fraktion am Landtagsausflug zwar von den meisten Rednern missbilligt, die Art und Weise wie die Angelegenheit von den Kritikern behandelt wurde, jedoch verurteilt $^{118}$. Die Stuttgarter Resolution wurde dort nicht angenommen. Diesem Meinungsbild entsprechen auch die Berichte aus anderen Vereinsversammlungen ${ }^{119}$.

Auf dem Parteitag zu Leipzig stellten die Stuttgarter einen Antrag, der die Teilnahme sozialdemokratischer Abgeordneter am Ausflug als einen „Verstoß gegen die Grundsätze der Partei “120 rügte. Nachdem die Abgeordneten erklärten, sie hätten nicht beabsichtigt, an einer monarchischen Demonstration mitzuwirken, zogen die Linken ihren Antrag zurück ${ }^{121}$. So blieb der Königsbesuch der Abgeordne-

115 „Parteiversammlung“, Schwäbische Tagwacht Nr. 187 vom 14. 8. 1909. S. 3.

116 „Parteiversammlung“, Schwäbische Tagwacht Nr. 187 vom 14. 8. 1909. S. 3.

117 „Parteiversammlung“, Schwäbische Tagwacht Nr. 187 vom 14. 8. 1909. S. 3.

118 „Aus der Partei“, Schwäbische Tagwacht Nr. 189 vom 17. 8. 1909. S. 5.

119 Auch in Reutlingen verurteilte die Mehrzahl der Anwesenden die Teilnahme ,an dieser höfischen Veranstaltung“, eine Resolution dagegen wurde jedoch abgelehnt, „weil man in der Hauptsache eine ruhigere Erledigung der Angelegenheit für wünschenswert hielt“; „Aus der Partei“, Schwäbische Tagwacht Nr. 189 vom 17. 8. 1909. S. 6. - In Esslingen sah man ebenso davon ab, eine Missbilligungsresolution zu verabschieden, wie sie von Jetter vorgelegt wurde: „Als Verteidiger der sieben Abgeordneten fand sich zwar niemand, nur brachten die Landtagsabgeordneten Kenngott und Schlegel zum Ausdruck, daß die ganze Sache des Aufhebens, das von ihr gemacht werde, nicht wert sei.“ „Aus der Partei“, Tagwacht Nr. 195 vom 24. 8. 1909. S.3.

120 Protokoll über die Verhandlungen des Parteitages der Sozialdemokratischen Partei Deutschlands. Abgehalten zu Leipzig vom 12. bis 18. September 1909. 1909. S. $194 \mathrm{f}$.

121 Protokoll (wie Anm. 120) S. 365. 
ten auf Reichsebene vorerst folgenlos. Auch auf der folgenden Landesversammlung wurde der Königsbesuch nicht missbilligt, die Radikalen mussten auch hier den Antrag zurückziehen ${ }^{122}$.

In der Stuttgarter Partei jedoch war das Vertrauen in die Abgeordneten schwer beschädigt und die Empörung über den Hofgang groß. Anders als in ländlichen Ortsvereinen verschonten sie die Stuttgarter nicht mit Vorwürfen und höhnischen Bemerkungen. Die Missbilligung durch den Parteitag und die Landesversammlung, die 1909 noch abgewendet wurde, erfolgte schließlich im Jahr darauf, im Zusammenhang mit einer erneuten Budgetbewilligung der badischen Fraktion.

\section{Der Eklat von 1910}

Nach dem „Hofgang“ der württembergischen Landtagsfraktion im Sommer 1909 stimmte die badische Fraktion im Jahr 1910 mit Verweis auf die vorliegenden „besonderen politischen Verhältnisse“, nämlich des badischen Großblocks, erneut für den Landesetat ${ }^{123}$. Es folgte ein Sturm der Entrüstung, erst vor zwei Jahren hatte in Nürnberg die Partei die Etatbewilligung der süddeutschen Abgeordneten missbilligt.

Auf der Stuttgarter Parteiversammlung vom 11. August 1910 stand „die traurige

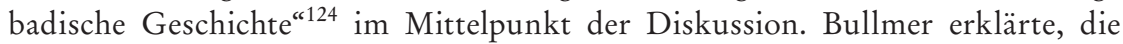
badische Fraktion habe bewusst die Disziplin gebrochen und „den Parteitagsbeschluss von Nürnberg zur Seite geschoben“" ${ }^{“ 25}$. Es scheine, als ob sich die „besonderen Verhältnisse" regelmäßig dann einstellten, wenn es galt, den Klassenkampfcharakter der Partei zu verwischen. Man wollte wohl dem Kleinbürgertum zeigen,

122 Vgl. Protokoll der Landesversammlung. In: Landesversammlung 1909. Bericht des Landesvorstandes, der Landtagsfraktion und Protokoll der Landesversammlung vom 8. und 9. Oktober in Stuttgart. O.J. [1909]. S. 222. - Lindemann bedauerte, der „sogenannte [...] Hofgang" einiger Fraktionsmitglieder sei unnötigerweise sehr aufgebauscht worden. Ähnlich wie in den Debatten über die Budgetbewilligung erklärte er, es habe keinen Anlass gegeben für eine „beabsichtigte Demonstration gegen den König“. Schließlich habe sich dieser „bisher als ein durchaus konstitutioneller Fürst gezeigt“. Außerdem bedeute „der Empfang unserer Fraktionsmitglieder durch den König [...] die Anerkennung unserer Partei als einer mit den übrigen Parteien gleichberechtigten durch den König“; ebd. S. 219.

${ }^{123}$ Vgl. „Parteiversammlung“, Schwäbische Tagwacht Nr. 186 vom 12. 8. 1910. S. 3. - Zum badischen Großblock vgl. Hans-Joachim Franzen: Die SPD in Baden 1900-1914. In: Die SPD in Baden-Württemberg und ihre Geschichte. Von den Anfängen der Arbeiterbewegung bis heute (Schriften zur politischen Landeskunde Baden-Württembergs 3). 1979. S. 88-106. - Der badische Großblock bestand aus Sozialdemokraten, Linksliberalen, Demokraten und Nationalliberalen. Die badische Fraktion erhoffte sich durch diese „parlamentarische Mehrheitskoalition“ die Gesetzgebung und Etatgestaltung stärker beeinflussen zu können; vgl. ebd. S. 92.

124 „Parteiversammlung“, Schwäbische Tagwacht Nr. 186 vom 12. 8. 1910. S. 2.

125 „Parteiversammlung“, Schwäbische Tagwacht Nr. 186 vom 12.8. 1910. S. 2. 
dass unter der sozialdemokratischen Löwenhaut lammfromme Leute steckten. In dem Maße, wie man glaube, hier etwas gewinnen zu können, würde man das Vertrauen in denkenden Arbeiterkreisen verlieren. „Wir lehnen das Budget nicht ab, weil uns der eine oder andere Teil des Budgets nicht gefällt, sondern weil wir prinzipielle Gegner der heutigen Staats- und Gesellschaftsordnung sind“, so Bullmer. Weiter erklärte er: „Die Regierungen arbeiten nur auf die Erhaltung der kapitalistischen Staatsordnung hin, die Minister sind Lohnarbeiter des Kapitals. Wenn wir nicht die Axt an die Wurzel unserer Kraft legen wollen, so dürfen wir mit dem Klassenstaat nichts gemein haben. [...] Wir verschütten damit die Quelle, aus der unsere Kraft fließt. Wir täuschen das Vertrauen der Arbeiterschaft. Man glaubt, die Sozialdemokratie regierungsfähig machen zu müssen dadurch, daß man, wie der Freisinn, Prinzipien über Bord wirft. Wer sich dem Programm, den Parteitagsbeschlüssen nicht fügt, der stellt sich selbst ausserhalb der Reihen des organisierten Proletariats, ausserhalb der Partei.“126

Hildenbrand entgegnete, die Nürnberger Resolution beweise selbst, dass die Budgetfrage eine Frage der Praxis und nicht des Prinzips sei, denn bei einem Prinzip gäbe es keine Ausnahmen ${ }^{127}$. Die Frage sei also zu stellen, ob es nicht besser sei, den Nürnberger Beschluss aufzuheben, um nicht für alle Zeiten festgelegt zu sein. „Es sei doch ein Unterschied zwischen einem preußischen und einem württembergischen Minister. (Großer Widerspruch.) Es wäre nicht möglich, in Württemberg dieselbe Taktik zu entfalten wie in Preußen.“ „Er erkläre“, so das Protokoll, „wenn er in Preußen wäre, dann wäre er viel radikaler als die preußischen Genossen (Große Heiterkeit.) [...] Es sei nicht richtig, wenn man die Budgetfrage als eine Frage des Radikalismus und Revisionismus bezeichne ${ }^{\text {"128 }}$.

Duncker erwiderte, die Handlung der badischen Fraktion sei eine „Überrumpelung der Partei“. Der Lebensnerv der Demokratie sei die Unterordnung der Minderheit unter den Willen der Mehrheit. Man müsse den Genossen, die sich derart gegen Programm und Parteitagsbeschlüsse vergingen, endlich einmal sagen: „Bis hierher und nicht weiter! “129

Die Stuttgarter Versammlung verabschiedete „mit sehr starker Mehrheit“ eine Resolution, die die Budgetbewilligung als „Verstoß gegen die prinzipielle Stellung der Sozialdemokratie zum Klassenstaat“ und als „bewusste Nichtachtung der Parteitagsbeschlüsse ${ }^{“ 130}$ verurteilte. Ferner wurde gefordert, dass der Parteitag in Magdeburg der Parteidisziplin Geltung verschaffen möge und die Einheit der Par-

126 „Parteiversammlung“, Schwäbische Tagwacht Nr. 186 vom 12.8. 1910. S. 3.

127 Hildenbrand spielt damit auf den Passus der Nürnberger Resolution an, nach dem das Budget dann bewilligt werden durfte, wenn „die Ablehnung desselben [...] die Annahme eines für die Arbeiterklasse ungünstigeren Budgets zur Folge haben würde“; Protokoll (wie Anm. 100) S. 550.

128 „Parteiversammlung“, Schwäbische Tagwacht Nr. 186 vom 12. 8. 1910. S. 3.

129 "Parteiversammlung", Schwäbische Tagwacht Nr. 186 vom 12. 8. 1910. S. 3.

130 „Parteiversammlung", Schwäbische Tagwacht Nr. 186 vom 12.8. 1910. S. 3. 
tei auf dem Boden des Programms und der Parteitagsbeschlüsse erhalte und festige $^{131}$.

Im Vorfeld des Magdeburger Parteitags forderten die württembergischen Abgeordneten eine Abänderung des Nürnberger Beschlusses, die Ablehnung des Budgets sollte nicht festgelegt werden ${ }^{132}$. Zu stürmischem Widerspruch führte die Aussage Hildenbrands, diese Forderung würde auch nicht verändert werden, wenn die Versammlung dazu Stellung nähme ${ }^{133}$.

In der Diskussion über „Die badische Budgetbewilligung“ auf dem Magdeburger Parteitag meldeten sich aus Stuttgart die Delegierten Hildenbrand, Keil, Westmeyer und Zetkin zu Wort ${ }^{134}$. Die Beiträge von Westmeyer und Zetkin zeigen, dass die Diskussion mittlerweile eine neue Qualität erlangt hatte.

Westmeyer sagte, dass wohl kein Zweifel darüber herrsche, dass nicht mehr um die Budgetbewilligung gestritten werde, sondern dass es sich um die prinzipielle Stellungnahme zum Klassenstaat handle. Und zwar, so Westmeyer, um die Frage: „Wollen wir wie bisher, fußend auf unseren alten grundsätzlichen Anschauungen, in schärfster Opposition bleiben oder wollen wir uns dem Klassenstaat anpassen.“135 „Budgetbewilligung, Hofgang, Ministeressen [...] das entspringt alles einer einzigen Wurzel, man kann es nicht trennen“"136, schlussfolgerte er.

Schließlich missbilligte der Magdeburger Parteitag die „monarchischen Kundgebungen“ und die Budgetbewilligung mit 228 zu 64 Stimmen in derselben Resolution $^{137}$. Ein Zusatzantrag verschärfte den Beschluss und erklärte, „daß [...] wenn abermals eine Missachtung der Resolution vorkommt, alsdann die Voraussetzungen des Ausschlussverfahrens gemäß $\$ 23$ des Organisationsstatuts gegeben sind “ 138 .

131 Vgl. „Parteiversammlung“, Schwäbische Tagwacht Nr. 186 vom 12. 8. 1910. S.3. Der Göppinger Ortsverein verabschiedete am selben Tag eine ähnliche Resolution; vgl. „Aus der Partei“, Tagwacht Nr. 187 vom 13. 8. 1910. S.3.

132 Vgl. „Parteiversammlung“, Schwäbische Tagwacht Nr. 218 vom 19. 9. 1910. S. 2.

133 „Sie können beschliessen, was sie wollen, die Fraktion wird handeln, wie sie es für richtig hält"; „Parteiversammlung“, Schwäbische Tagwacht Nr. 218 vom 19. 9. 1910. S. 2.

134 Vgl. Protokoll über die Verhandlungen des Parteitages der Sozialdemokratischen Partei Deutschlands. Abgehalten in Magdeburg vom 18. bis 24. September 1910. 1910. S. 279341.

135 Protokoll (wie Anm. 134) S. 340.

136 Protokoll (wie Anm. 134) S. 340.

137 Protokoll (wie Anm. 134) S. 383.

138 Protokoll (wie Anm. 134) S. 488. - Die Resolution berief sich auf die Beschlüsse von Lübeck, Dresden und Nürnberg, die Budgetbewilligung der badischen Abgeordneten wurde als eine „bewusst herbeigeführte grobe Missachtung der [...] Parteitagsbeschlüsse und eine schwere Verfehlung gegen die Einheit der Partei [...]“ verurteilt und ihr „die allerschärfste Missbilligung" ausgesprochen. Die Teilnahme an höfischen Zeremonien und monarchischen Loyalitätskundgebungen wurde „für unvereinbar mit [...] sozialdemokratischen Grundsätzen“ erklärt. Die Mitglieder wurden verpflichtet „solchen Kundgebungen fernzubleiben“; ebd. 
Auf der Parteiversammlung vom 29. September erstattete Westmeyer Bericht vom Magdeburger Parteitag. In der Debatte sprachen sich Kinkel (der aus Göppingen gekommen war), Bratz, Roßmann und Zetkin für den Magdeburger Beschluss aus. Bratz sagte, der Arbeiter in der Werkstatt könne genau so urteilen, wie der im Parlament. Wenn jemand aus Not einen Streikbruch begehe, dann würde er ausgeschlossen. So solle es auch bei den führenden Funktionären der Sozialdemokratie $\operatorname{sein}^{139}$. Heymann und Keil, die den Magdeburger Beschluss für unhaltbar erklärten, vermochten es nicht, die Mehrheit von ihrer Position zu überzeugen. Gegen 13 Stimmen und zahlreiche Enthaltungen sprach die Versammlung „ihre volle Übereinstimmung mit den Beschlüssen des Parteitags aus und verpflichtet[e] jeden $\mathrm{Ge}$ nossen, im Sinne dieser Beschlüsse zu wirken “140. Mit den Magdeburger Beschlüssen erklärten sich auch die Ortsvereine Gerlingen, Göppingen ${ }^{141}$ und Cannstatt ${ }^{142}$ ausdrücklich einverstanden.

Der Magdeburger Beschluss stellte wie schon die Nürnberger Resolution von 1908 unmissverständlich klar, dass die Budgetbewilligung keine taktische, sondern eine prinzipielle Frage war. Anders als im Nürnberger Beschluss wurde nun allerdings bei Missachtung mit einem Ausschlussverfahren gedroht. Offensichtlich zeigte der Magdeburger Beschluss Wirkung. Bis 1914 stimmte weder in Württemberg noch in Bayern ein Sozialdemokrat dem Staatshaushalt zu. Dass die Budgetbewilligung in Baden gegen die Beschlüsse von Nürnberg verstieß, konnten auch die gemäßigten Mitglieder nicht leugnen. So vertraten sie die Meinung, dass der Beschluss rückgängig gemacht werden müsse ${ }^{143}$.

Diese Haltung verstanden die Radikalen als Aufweichung der bisherigen Positionen der Partei. Sie sahen in der erneuten Budgetbewilligung - abgesehen von einem Disziplinbruch - die grundlegende Haltung zum kapitalistischen „Klassenstaat“ revidiert. Die Frage, ob und wie der Staat bekämpft werden müsse, die sich im selben Jahr auch in der Massenstreikdiskussion als grundlegende Kontroverse äußerte, sollte in Folge des drohenden Weltkrieges ein nie gekanntes Ausmaß erreichen.

139 Vgl. „Berichterstattung vom Parteitag“, Schwäbische Tagwacht Nr.229 vom 1.10. 1910. S. 9 f.

140 „Aus der Partei“, Schwäbische Tagwacht Nr. 228 vom 30. 9. 1910. S. 9.

141 „Aus der Partei“, Schwäbische Tagwacht Nr. 232 vom 5.10. 1910. S. 7.

142 „Aus der Partei“, Schwäbische Tagwacht Nr. 244 vom 19. 10. 1910. S. 6.

143 Erneut verwiesen sie auf die Unterschiede der süd- und norddeutschen Regierungen. Beschlüsse der Gesamtpartei sollten demnach nicht automatisch auch für Süddeutschland gelten bzw. sollten so gefasst werden, dass sie den süddeutschen Landesparteien Ausnahmen gewähren. 


\section{Prinzipielle Uneinigkeiten}

Am 4. Februar 1910 veröffentlichte die preußische Regierung eine Wahlrechtsvorlage, die das Dreiklassenwahlrecht - entgegen aller Erwartungen und Hoffnungen - unangetastet ließ. Am 13. Februar kam es in etlichen Städten Preußens zu Protestversammlungen und Demonstrationszügen, die auch zu Zusammenstößen mit der Polizei führten ${ }^{144}$ und „die Basis der Wahlrechtsbewegung bis weit ins Bürgertum hinein ${ }^{\text {“145 }}$ verbreiterte. Die Zuspitzung der Wahlrechtsbewegung, entfachte erneut die Massenstreikdebatte. Anders als in den Jahren 1904 bis 1906, stand nun die konkrete „Anwendbarkeit des politischen Massenstreiks im preuBischen Wahlrechtskampf “"146 zur Entscheidung. Ob reichsweit, in Württemberg oder in Stuttgart: Die Auseinandersetzungen wurden härter, schärfer und unnachgiebiger ${ }^{147}$.

Die Sozialdemokratie reagierte zwischen Februar und April mit „einer der längsten Perioden der Agitation, die die Partei je erlebt hatte ${ }^{\text {«148 }}$; die Parteileitung leitete den Wahlrechtskampf jedoch „ohne konkrete, taktische Vorstellung “149 ein und beschloss, die Frage des Massenstreiks nicht zu erörtern ${ }^{150}$. Als führende Persönlichkeit der reichsweiten Parteilinken vertrat Rosa Luxemburg den Standpunkt, die preußische Wahlrechtsbewegung müsse zum politischen Massenstreik und schließlich zur sozialen Revolution ausgeweitet werden ${ }^{151}$.

Es entspannte sich ein heftiger Streit um die richtige Taktik, infolge dessen sich der linke Flügel der Partei in ein linkes Zentrum und in eine linksradikale Gruppe zu teilen begann ${ }^{152}$. In der württembergischen Partei wurde diese „Dreiteilung“ der Partei nicht sichtbar. Stattdessen verhärteten sich die Gegensätze zwischen Reformisten und Radikalen, wobei sich Letztere an Rosa Luxemburg und der Parteilinken orientierten. So unterstützten sie auf dem Magdeburger Parteitag von 1910 eine von Luxemburg vorgelegte Resolution, nach der die Massenstreikagitation zur Aktivierung der Massen genutzt werden sollte, um Druck auf die Parteileitung

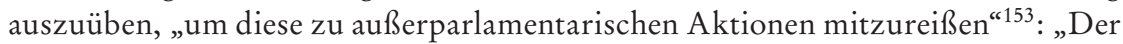
Parteitag erklärt [...], daß der Wahlrechtskampf in Preußen nur durch eine große, entschlossene Massenaktion des arbeitenden Volkes zum Siege geführt werden

144 Vgl. Grob (wie Anm. 81) S. 140 f. und Schorske (wie Anm. 27) S. 232 f.

145 Grob (wie Anm. 81) S. 135.

146 Grob (wie Anm. 81) S. 184.

147 Wie eingangs erwähnt war Westmeyer seit zwei Jahren Vorsitzender der Stuttgarter Partei.

148 Vgl. Schorske (wie Anm. 27) S.230f.

149 Groh (wie Anm. 81) S. 133.

150 Grob (wie Anm. 81) S. 137 f.

151 Grob (wie Anm. 81) S. 144.

152 Zum Prozess der Herausbildung des linken Zentrums innerhalb der Gesamtpartei vgl.

Grob (wie Anm. 81) S. 144, 156-160 und 186-192.

153 Grob (wie Anm. 81) S. 170. 
kann, wobei alle Mittel, darunter auch der politische Massenstreik, nötigenfalls zur Anwendung gebracht werden müssen. Angesichts dessen erklärt der Parteitag für notwendig, im Hinblick auf die künftige Wiederaufnahme der Wahlrechtskampagne die Erörterung und Propagierung des Massenstreiks in der Parteipresse und in Versammlungen in die Wege zu leiten und so in den breitesten Schichten des Proletariats das Gefühl der eigenen Macht sowie das politische Bewusstsein zu schärfen, damit die Massen den großen Aufgaben gewachsen sind, wenn die Situation es erfordert. “" 154

Clara Zetkin verteidigte die Resolution im Plenum und betonte, es gehe nicht darum, den Massenstreik unmittelbar umzusetzen, denn dieser müsse spontan entstehen. Genau deshalb aber, weil er nicht planbar sei, müsse im Vorfeld so viel wie möglich an Aufklärungsarbeit geleistet werden: „Es handelt sich absolut nicht darum [...] den Massenstreik für einen bestimmten Zeitpunkt oder aber schon jetzt für eine Eventualität anzukündigen. [...] Aber gerade weil wir mit der Tatsache rechnen müssen, daß in dem Proletariat unter bestimmten historischen Umständen das Bewusstsein seiner entscheidenden Macht erwacht [...] gilt es, gerüstet zu sein. Die Resolution soll nur der Anreiz sein, nur die moralische Ermutigung, den Gedanken des Massenstreiks [...] immer mehr dorthin zu tragen, wo eines Tages die Entscheidung über die Möglichkeit und Notwendigkeit seiner Verwirklichung fallen wird: unter die Massen selbst! “ 155

Weiter sagte sie: „Die vorhandene Stimmung müssen wir ausnutzen [...]. Solche Zeiten tiefer politischer Gärung und Bewegung sind am besten geeignet, den Massen das Bewusstsein für ihre Rolle im gesellschaftlichen Produktionsprozeß zu schärfen.“ ${ }^{* 156}$

Vor der Abstimmung zogen die Antragsteller den zweiten Absatz zurück. Mit der Annahme des ersten Absatzes in Verbindung mit der vorausgegangen Diskussion sei das Ziel erreicht, welches sie im gegenwärtigen Augenblick ins Auge gefasst hätten ${ }^{157}$. Der erste Absatz wurde schließlich vom Parteitag angenommen ${ }^{158}$. So wurde aber erneut eine Resolution verabschiedet, die den Massenstreik nur prinzipiell befürwortete, jedoch keine konkreten Schritte für seine Propagierung vorschlug.

Zurück in Stuttgart verteidigte Westmeyer in einer Parteiversammlung die Resolution, die auch er unterzeichnet hatte. Während es in einem Leitartikel der Schwäbischen Tagwacht hieß, dass es ein „Akt der Klugheit“ gewesen sei, eine Abstimmung über die Resolution der Genossin Luxemburg zu vermeiden, erklärte

\footnotetext{
154 Protokoll (wie Anm. 134) S. $181 \mathrm{f}$.

155 Protokoll (wie Anm. 134) S. $443 \mathrm{f}$

156 Protokoll (wie Anm. 134) S. 443 f.

157 Protokoll (wie Anm.134) S. 450. - Offen bleibt, ob ihr Anliegen tatsächlich erreicht wurde oder ob lediglich erkannt wurde, dass es für den zweiten Absatz keine Mehrheit geben würde.

158 Protokoll (wie Anm. 134) S. 489.
} 
Westmeyer, der Antrag sollte dazu dienen, die Massen mit dem politischen Massenstreik vertraut zu machen. Denn die Wahlrechtsfrage in Preußen und die Polizeigewalt zeige, dass der Kapitalismus prinzipienfester sei als seine Gegner. Es sei wünschenswert, dass diese ebenso prinzipienfest wären. Der Kapitalismus könne nicht stückweise niedergezwungen werden, sondern müsse in seiner Gesamtheit durch die Massen der Arbeiter vernichtet werden ${ }^{159}$. Damit unterstrich Westmeyer seine Ablehnung reformistischer Politik und der Auffassung, den kapitalistischen Staat „stückweise“, durch Reformen, umformen zu können.

Die Stuttgarter Radikalen suchten in diesem allgemeinen Richtungsstreit stets die Zusammenarbeit mit prominenten Vertretern des linken Parteiflügels. So luden sie den Bremer Linksradikalen, Theoretiker und Journalist Anton Pannekoek ein und veranstalteten mit ihm mehrere Versammlungen zum Thema „Die Machtmittel des Proletariats“. Die Einladung Pannekoeks nach Stuttgart war ein Affront gegen die reformistischen Stimmen in der Landespartei. Pannekoeks radikale Positionen sollten in der Mitgliedschaft verbreitet werden: Die friedliche Eroberung der Staatsgewalt auf parlamentarischem Wege sei, so Pannekoek, „nur eine Illusion“, wohingegen der Massenstreik als eines der „schärfsten Waffen des Proletariats“ imstande sei „die Zerstörung der Organisation des Staates“ zu erreichen ${ }^{160}$.

Nur knapp zwei Wochen nach Pannekoeks Besuch widersprach Karl Hildenbrand in der Artikelserie „Alte oder neue Taktik“ den Ausführungen Pannekoeks $^{161}$ : „Widerspricht es nicht allen traditionellen Anschauungen der Partei, dass wir die ,Staatsgewalt zerstören' wollen? Wir wollen nicht zerstören, sondern erobern und aufbauen. Dass wir nicht eine Partei des ,Umsturzes', der ,Zerstörung“ sind, ist in Deutschland schon so oft betont worden, dass auch Pannekoek es wissen könnte. “162

In den Debatten ging es längst nicht mehr nur um die Frage „Massenstreik - ja oder nein“. Prinzipielle Uneinigkeiten kamen zur Sprache: Wie sollte der Kapitalismus überwunden werden? Sollte er überhaupt beseitigt werden? Und was war eigentlich das Selbstverständnis der Partei? Die Polarisierung in der württembergischen Partei schritt weiter fort.

159 Vgl. „Berichterstattung vom Parteitag“, Schwäbische Tagwacht Nr.229 vom 1.10. 1910. S. 9.

160 „Die Machtmittel des Proletariats“, Schwäbische Tagwacht Nr. 257 vom 3. 11. 1910. S. 1 und 5.

161 Vgl. „Alte oder neue Taktik“, Schwäbische Tagwacht Nr. 265 vom 12.11. 1910. S.1; „Alte oder neue Taktik“, Tagwacht Nr. 266 vom 14.11. 1910. S.1. - Hildenbrands Artikel folgte eine Antwort Pannekoeks (Vgl. dazu „Parlamentarismus und Massenstreik“, Tagwacht Nr. 281 vom 1.12. 1910. S.1-2. - „Parlamentarismus und Massenstreik“, Tagwacht Nr. 282 vom 2.12. 1910. S. 1. - „Parlamentarismus und Massenstreik“, Tagwacht Nr. 283 vom 3.12. 1910. S. 1.). Nur zwei Tage später folgte ein weiterer Artikel Hildenbrands; vgl. „Die Taktik Pannekoeks und die der Partei“, Tagwacht Nr. 284 vom 5. 12. 1910. S. 1.

162 „Die Taktik Pannekoeks und die der Partei“, Schwäbische Tagwacht Nr. 284 vom 5.12. 1910. S.1. 


\section{Dem Militarismus keinen Groschen?}

Seit jeher war die Bekämpfung von Militarismus und Kriegsgefahr eines der Hauptziele der deutschen wie auch der internationalen Sozialdemokratie gewesen, stets in Verbindung mit der Forderung nach einer sozialistischen Gesellschaftsalternative ${ }^{163}$. Mit Eintritt Deutschlands in die „Weltpolitik“ seit dem ausgehenden 19. Jahrhundert ${ }^{164}$, versinnbildlicht in dem von Bülow propagierten „Platz an der Sonne “165, verabschiedete die Sozialdemokratie diverse Resolutionen und Stellungnahmen, die sich gegen Aufrüstung und Militarismus richteten ${ }^{166}$. Auch der internationale Sozialistenkongress in Stuttgart von 1907 - das europäische Wettrüsten war mittlerweile in vollem Gange ${ }^{167}$ - fasste einen Beschluss zur Bekämpfung von Krieg und Kriegsgefahr ${ }^{168}$. Bis Kriegsbeginn wurde die Stuttgarter Resolution durch die internationalen Beschlüsse von Kopenhagen 1910 und Basel 1912 bestätigt $^{169}$.

163 Vgl. die Beschlüsse verschiedener Internationaler Sozialistenkongresse: 1867 (Lausanne), 1868 (Brüssel), 1893 (Zürich), 1896 (London), Paris (1900); vgl. „Beschlüsse Internationaler Sozialistenkongresse gegen den Krieg“, Schwäbische Tagwacht Nr. 171 vom 27. 7. 1914. S.1. - Sowie Außerordentlicher Internationaler Sozialistenkongress zu Basel (24. und 25. November 1912). In: Kongressprotokolle der Zweiten Internationale. Bd.2: Stuttgart 1907 - Basel 1912. ND 1976. S. 43-51 („Die Resolutionen der Arbeiter-Internationale gegen den Krieg [1867-1910]“).

164 Vgl. Peter März: Der Erste Weltkrieg. Deutschland zwischen dem langen 19. Jahrhundert und dem kurzem 20. Jahrhundert (Berlin \& München - Studien zu Politik und Geschichte 1). 2004. S. 26.

165 Bernhard von Bülow, Staatssekretär des Auswärtigen Amtes, in seiner Reichstagsrede vom 6.12. 1897; vgl. Oliver Stein: Die deutsche Heeresrüstungspolitik 1890-1914. Das Militär und der Primat der Politik (Krieg in der Geschichte 39). 2007. S. 386.

166 Militarismus sei „eine fortdauernde Bedrohung des Völkerfriedens [...] deren Zweck die wirtschaftliche Ausbeutung und die politische Niederhaltung der Arbeiterklasse ist“; Protokoll über die Verhandlungen des Parteitages der Sozialdemokratischen Partei Deutschlands. Abgehalten zu Berlin vom 14. bis 21. November 1892. 1892. S. 132 und 145. - Gegen Soldatenmisshandlungen wandte sich die Resolution Nr. 143 des Bremer Parteitags von 1904; vgl. Protokoll über die Verhandlungen des Parteitages der Sozialdemokratischen Partei Deutschlands. Abgehalten zu Bremen vom 18. bis 24. September 1904. 1904. S. 319.

167 Vgl. März (wie Anm. 164) S.30f.

168 Der „Kampf gegen den Militarismus“ könne nicht getrennt werden vom „sozialistischen Klassenkampf“. Es sei die „Pflicht der arbeitenden Klasse und insbesondere ihrer Vertreter in den Parlamenten [...] mit allen Kräften die Rüstungen zu Wasser und zu Lande zu bekämpfen und die Mittel hierfür zu verweigern"; Internationaler Sozialistenkongress zu Stuttgart (18. bis 24. August 1907). In: Kongressprotokolle (wie Anm. 163) S. 64 f. - Drohe der Ausbruch eines Krieges, so sei alles aufzubieten, um durch die Anwendung der am wirksamsten erscheinenden Mittel den Ausbruch des Krieges zu verhindern. Falls der Krieg dennoch ausbrechen sollte, sei es die Pflicht, für dessen rasche Beendigung einzutreten und mit allen Kräften dahin zu streben, die durch den Krieg herbeigeführte wirtschaftliche und politische Krise zur Aufrüttelung des Volkes auszunutzen und dadurch die Beseitigung der kapitalistischen Klassenherrschaft zu beschleunigen“; ebd. S. 66.

${ }_{169}$ Vgl. Internationaler Sozialistenkongress zu Kopenhagen (28. August bis 3. September 
Als im Frühjahr 1913 im Reichstag die Verabschiedung einer neuen Heeresvorlage bevorstand, entzündete sich innerhalb der Sozialdemokratie eine neue Streitfrage. Reichsregierung und Reichskanzler warben in einer umfassenden Propagandawelle für eine weitere Verstärkung des Heeres ${ }^{170}$. Die Finanzierung sollte durch einen vom Vermögen aufzubringenden Wehrbeitrag und durch eine direkte Reichsvermögenszuwachssteuer erfolgen ${ }^{171}$. Sollte die Fraktion im Reichstag der Heeresvorlage zustimmen?

Der entsprechende Gesetzentwurf wurde am 28. März dem Reichstag vorgelegt - noch am selben Tag rief die Stuttgarter Parteileitung zu einer „Demonstrationsversammlung “ auf dem Stuttgarter Marienplatz auf ${ }^{172}$. Sie trat für eine Ablehnung der neuen Heeresvorlage ein "ganz gleich, in welcher Form die Deckung geplant

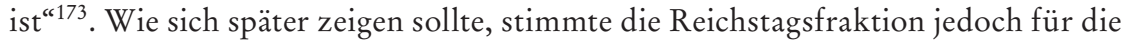
Deckungsvorlage - die keine indirekten Steuern vorsah - um die Rüstungskosten auf bessergestellte Bevölkerungsschichten zu verlagern ${ }^{174}$.

Die Radikalen forderten eine Verschärfung und Erweiterung des Kampfes gegen die Rüstungsvorlage, und konnten diesen Standpunkt auf der Kreisversammlung des 1. württembergischen Reichstagswahlkreises vom 25. Mai durchsetzen. Die dort verabschiedete Resolution bedauerte, „daß der Kampf gegen die Militärvorlage im Parlament nicht energischer geführt wird“ und hielt darüber hinaus „auch den seitherigen, außerhalb des Parlaments geführten Kampf für ungenügend “175. Von der Reichstagsfraktion erwartete die Versammlung, „daß bei den Verhandlungen im Plenum [Reichstag, die Verf.] der Kampf in schärfster Form einsetzte, wenn nötig durch Obstruktion“. Der Parteivorstand solle zudem „eine die ganze arbeitende Bevölkerung erfassende Aktion, eventuell den Massenstreik in die Wege

1910). In: Kongressprotokolle (wie Anm.163) S.34f. - Sowie Sozialistenkongress (wie Anm. 163) S. 23.

$170 \mathrm{Vgl}$. Stein (wie Anm. 165) S. $346 \mathrm{f}$.

171 Vgl. Stein (wie Anm. 165) S. 353.

172 Vgl. „Diesem System keinen Mann und keinen Groschen“, Schwäbische Tagwacht Nr. 71 vom 28.3. 1913. S. 1. - „Von der Abwehr zum Angriff!“, lautete die Parole, die Abwehr von Militarismus müsse verbunden werden mit der offensiven Bekämpfung des Kapitalismus. Ein „planmäßiger Generalsturm auf der ganzen Linie“ sei zu organisieren, durch „wuchtige Massenaktionen“ mit entsprechenden Steigerungen; vgl. ebd. - Bezüglich der Heeresvorlage hieß es: „Wir hoffen, dass unsere Genossen im Reichstage nicht nur die Heeresvorlage grundsätzlich ablehnen werden, sondern daß sie auch ebenso grundsätzlich die Deckungsvorlagen, ganz gleich, ob sie offene indirekte Steuern, oder verkappte indirekte Steuern, oder sogenannte direkte, angebliche Besitzsteuern enthalten. Sind wir grundsätzlich Gegner des Militarismus, dann dürfen wir auch keinen Pfennig für ihn bewilligen, ganz gleich, in welcher Form die Deckung geplant ist.“ „Diesem System keinen Mann und keinen Groschen“, Tagwacht Nr. 71 vom 28.3. 1913. S.1.

173 „Diesem System keinen Mann und keinen Groschen“, Schwäbische Tagwacht Nr. 71 vom 28.3.1913. S.1.

174 Vgl. Groh (wie Anm. 81) S. 435.

175 „Aus der Partei“, Schwäbische Tagwacht Nr. 120 vom 27.5. 1913. S. 6. 
leiten“176. Die Unterzeichner forderten damit eine Verbindung von parlamentarischer und außerparlamentarischer Aktion und „daß die ersten Worte einer scharfen und umfassenden Aktion gesprochen werden“. In diesem Zusammenhang rückte auch die Forderung nach der Propagierung von Massenstreiks in ein neues Licht ${ }^{177}$.

Als die sozialdemokratische Reichstagsfraktion am 30. Juni 1913 der Deckungsvorlage zustimmte ${ }^{178}$, verschärften sich die innerparteilichen Kontroversen. Die Stuttgarter Linken prangerten die zunehmende Orientierung auf parlamentarische Aktivitäten an und forderten eine stärkere Hinwendung zu Massenaktivitäten. Es werde nicht genügend beachtet, hieß es in einem Artikel der Schwäbischen Tagwacht, dass die Sozialdemokratie nicht ein Wahlverein sei, der lediglich Wahlkämpfe vorzubereiten und zu führen habe. Der Parlamentarismus dürfe nicht zum A und O der Sozialdemokratie werden, an erster Stelle stehe der „rücksichtslose Klassenkampf“179. Ein Artikel vom 10. Juli beklagte die „Dämpfungspolitik“ der Partei ${ }^{180}$. Bevor man sich frage, wo die Massen blieben, müsse sich die Partei über ihre eigene Taktik klar werden sowie über Wesen und Bedeutung von Massenaktionen. Diese würden nur aus einer prinzipiellen Kampftaktik heraus entstehen und könnten zwar von der Partei nicht besonders erzeugt, sehr wohl aber verdorben werden, etwa wenn das Vertrauen in eine entschiedene Führung durch die Partei erschüttert sei ${ }^{181}$.

Die Haltung Rosa Luxemburgs, die der „parlamentarischen Strategie“ der Reformisten eine revolutionsstrategische Massenstreikkonzeption entgegenstellte ${ }^{182}$, unterstützten die Stuttgarter Radikalen. Ein Massenstreik sollte in mehreren Etappen auf eine soziale Revolution hinarbeiten und statt eines kurzfristigen taktischen Mittels Teil einer langfristigen Strategie zum Umsturz des Kapitalismus $\operatorname{sein}^{183}$.

176 „Aus der Partei“, Schwäbische Tagwacht Nr. 120 vom 27. 5. 1913. S. 6. - An der Versammlung nahmen 148 Delegierte von 25 Ortsvereinen teil sowie einzelne Abgeordnete und Gäste aus dem 2. Wahlkreis. Die Resolution wurde einstimmig angenommen; vgl. ebd. S.6.

177 „Unser Kampf gegen die Rüstungsvorlage“, Schwäbische Tagwacht Nr. 124 vom 31.5. 1913. S. 1. - Der Massenstreik sollte nun nicht mehr nur zur Erkämpfung des Wahlrechts propagiert werden, sondern wurde auch als Höhepunkt einer Massenbewegung gegen den drohenden Krieg zum Ziel erklärt. Obstruktion und Massenstreik seien demnach nicht die unmittelbar realisierbaren Schritte, sehr wohl aber die „natürlichen Endpunkte von Aktionen, die vom gegebenen Stadium des Kampfes aus einsetzen und ihn nach Energie und Umfang ständig steigern"; ebd.

178 Vgl. Stein (wie Anm. 165) S. 353.

179 „Zur allgemeinen Taktik der Sozialdemokratie“, Schwäbische Tagwacht Nr. 145 vom 25.6. 1913. S. 1 .

180 Der Artikel spricht von „Depression im Parteileben“, von flauer Stimmung und Gleichgültigkeit in der Partei und von einer Stagnation der Mitgliederzahlen; vgl. „Flaue Stimmung“, Schwäbische Tagwacht Nr. 158 vom 10.7. 1913. S.1.

181 Vgl. „Flaue Stimmung“, Schwäbische Tagwacht Nr. 158 vom 10.7. 1913. S. 1.

182 Vgl. Grob (wie Anm. 81) S. 477 f.

183 Vgl. Groh (wie Anm. 81) S. 478 ff. - So schrieb Clara Zetkin: „In Zeiten scharf zuge- 
Das Verhalten der Reichstagsfraktion zur Militärvorlage verurteilte Crispien im Hinblick auf den anstehenden Parteitag in einer Stuttgarter Mitgliederversammlung als „ein klassisches Muster reinster Opportunitätspolitik “184. Es sei eine unheilvolle Verblendung, wenn man annehme, die Besitzenden würden wirklich die Lasten der sogenannten Besitzsteuer tragen. Diese neue Steuer als Erfolg der sozialdemokratischen Taktik anzusehen, sei Selbsttäuschung. Die besitzenden Klassen würden es verstehen, auch die neuen Besitzsteuern in Form von Lohnkürzungen, neuer Handelsverträge oder Preiserhöhungen auf das arbeitende Volk abzuwälzen. Die sozialdemokratische Forderung nach direkten statt indirekten Steuern, auf die sich nun die Fraktion berufe, bedeute nicht, dass jede direkte Steuer zu bewilligen sei. Der Militarismus sei eine Lebensfrage der kapitalistischen Wirtschaftsordnung. Deshalb hätte die Fraktion unter keinen Umständen den neuen Steuern zustimmen dürfen ${ }^{185}$. Crispien verwies auf die Dresdner Resolution und sprach die Hoffnung aus, dass diese auf dem Parteitag bekräftigt werde. Von einer Beschlussfassung sah die Versammlung zwar ab, doch der stürmische Beifall, unter dem Crispien seinen Vortrag beendete, zeugt von großer Zustimmung.

Auf dem Jenaer Parteitag von 1913 erfolgte eine Aussprache über die Bewilligung der Militärkosten durch die Reichstagsfraktion. Eine Resolution der Linken forderte den äußersten Kampf gegen Militarismus und dass alle Gesetzesvorlagen, die zur Deckung der Militärkosten im Reichstag eingebracht würden, abzulehnen seien $^{186}$. Crispien und Westmeyer unterstützten diese Resolution und lehnten die des Parteivorstandes $a b^{187}$. Eine weitere Resolution der Linken begrüßte das „wiedererwachte Interesse weiter Parteikreise an der Frage des politischen Massenstreiks“ und forderte als „Antwort auf die Übergriffe der Reaktion wie als erste Voraussetzung erfolgreicher Massenaktionen [...] eine offensive, entschlossene und konsequente Taktik der Partei auf allen Gebieten, die den Schwerpunkt des Kampfes bewusst in die Aktion der Massen verlegt “"188. Der Antrag, der mit 333 gegen 142 abgelehnt wurde, wurde von den Stuttgartern mehrheitlich unterstützt ${ }^{189}$.

spitzter Klassengegensätze und Klassenkämpfe tritt der Massenstreik als die klassische Bewegungs- und Kampfesform des Proletariats auf. Er ist der Ausdruck des Bewusstseins der Ausgebeuteten von den Forderungen, die sie an die bürgerliche Gesellschaft zu stellen haben, und der Macht, die sie hinter ihre Forderungen setzen können und restlos einzusetzen gewillt sind“. Als „schärfstes Mittel des proletarischen Klassenkampfes“ müsse sich der Massenstreik „einer festgegliederten, unzerreisslichen Kette schärfsten grundsätzlichen Klassenkampfes einfügen“; „Um die sozialdemokratische Taktik“, Schwäbische Tagwacht Nr. 156 vom 8. 7. 1913. S. 1.

184 „Der bevorstehende Parteitag“, Schwäbische Tagwacht Nr. 189 vom 15. 8. 1913. S. 10.

185 „Der bevorstehende Parteitag“, Schwäbische Tagwacht Nr. 189 vom 15. 8. 1913. S. 10.

186 Vgl. Protokoll über die Verhandlungen des Parteitages der Sozialdemokratischen Partei Deutschlands. Abgehalten in Jena vom 14. bis 20. September 1913. 1913. S. 192.

187 Vgl. Protokoll (wie Anm. 186) S. 174.

188 Protokoll (wie Anm. 186) S. 194.

189 Protokoll (wie Anm. 186) S. 146. 
Auf den Stuttgarter Parteiversammlungen vom 26. September und 2. Oktober bilanzierten die Mitglieder die Ergebnisse des Parteitags. Gegen 15 Stimmen wurde eine Resolution verabschiedet, die das volle Einverständnis mit der Haltung ihrer Delegierten Crispien und Westmeyer auf dem Parteitag erklärte. Man bedauerte, dass die Mehrheit des Parteitages „den konsequenten Kampf gegen das stärkste Bollwerk des Klassenstaats, den mörderischen Militarismus, durch ihre Entscheidung in der Steuerfrage erschwert [und] das Vertrauen weiter Kreise der Arbeiterschaft $\mathrm{zu}$ unserer prinzipiellen Ablehnung des imperialistischen Rüstungswahnsinns erschüttert hat ${ }^{\text {"190 }}$.

Die Versammlung sprach zudem „den 140 Delegierten den Dank aus, die sich in der [...] Massenstreikfrage der Dämpfungstaktik der Mehrheit entschlossen widersetzten, einer Taktik, die letzten Endes auf die Umwandlung der Sozialdemokratie als einer revolutionären Klassenkampfpartei zu einer radikalen Reformpartei hi-

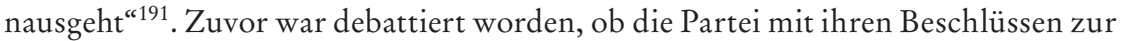
Militärvorlage und zum Massenstreik nach rechts gerutscht sei, oder ob sie sich lediglich gegebenen Verhältnissen angepasst habe.

Westmeyer verurteilte die Parteitagsbeschlüsse und die Haltung der Reichstagsfraktion und konstatierte, dass die „Opportunisten und Reformisten in der Partei [...] in Jena zweifellos einen Sieg errungen [haben] “192. Nun müsse sich zeigen, ob die Massen gewillt seien, diesen Weg weiterzugehen oder ob die Partei bleiben solle, was sie bisher gewesen sei: die „Todfeindin der bürgerlichen Gesellschaft“. Der „Flaumacherei“ des Parteivorstandes müsse eine offensive Taktik entgegengestellt werden, die den Schwerpunkt des Kampfes auf die Aktion der Massen verlege.

Unter den vielen Rednern kritisierten auch Crispien, Heidinger, Schlör und Oster die Haltung der Reichstagsfraktion. Bemerkenswert ist die Wortmeldung eines weiteren Mitglieds: Schumacher mahnte, man solle sich hüten, den Weg des Opportunismus zu gehen. Denn die Massen würden dann „eine neue revolutionäre Partei bilden“. „Und sie täten recht daran“193, bekräftigte er.

Die Auseinandersetzungen zeigen, dass sich die Kritik der Stuttgarter Radikalen nicht mehr nur auf die Haltung württembergischer Reformisten oder süddeutscher Landtagsfraktionen beschränkte, sondern auf die allgemeine Ausrichtung der Partei ausdehnte. Auf den Parteitagen unterstützten sie die Resolutionen der reichs-

190 „Stuttgart“, Schwäbische Tagwacht Nr. 231 vom 3.10. 1913. S. 3. - Zum Massenstreik hieß es: „Die Versammelten sind in der Massenstreikfrage nach wie vor der Überzeugung, dass nur eine entschlossen angreifende Taktik, die den Schwerpunkt des Kampfes aus dem Parlament in die Aktion der Massen selbst verlegt, geeignet ist, in der Arbeiterschaft die Kampfenergie und den Idealismus wach zu halten, die Angriffe der Gegner abzuwehren und mehr Recht zu erobern“; ebd.

191 „Stuttgart", Schwäbische Tagwacht Nr. 231 vom 3.10. 1913. S. 3.

192 „Sozialdemokratischer Verein Stuttgart“, Schwäbische Tagwacht Nr. 228 vom 30.9. 1913. S. 9.

193 „Sozialdemokratischer Verein Stuttgart“, Schwäbische Tagwacht Nr.233 vom 6.10. 1913. S.3. 
weiten Parteilinken, wo sie mittlerweile selbst ein wichtiger Faktor geworden waren. Als Teil dieser reichsweiten innerparteilichen Opposition agierten sie schließlich auch, als mit Beginn des Ersten Weltkrieges die ideologische Polarisierung krasser als je zuvor in Erscheinung trat.

\section{August 1914 - die politischen Gegensätze werden unüberbrückbar}

Kurz vor der Kriegserklärung Österreich-Ungarns an Serbien am 28. Juli $1914^{194}$ verabschiedete die Landesversammlung der württembergischen Sozialdemokraten noch folgende Resolution: „Der Ausbruch des Krieges zwischen Oesterreich und Serbien stellt Europa an den Rand einer Katastrophe. [...] Die Landesversammlung der Sozialdemokraten Württembergs erkennt den furchtbaren Ernst des Augenblicks und beauftragt den Landesvorstand, unverzüglich eine Aktion einzuleiten, die durch Volksversammlungen den Friedenswillen des Proletariats bis ins kleinste Dorf leitet. Diese Aktion soll eingeleitet werden durch ein Flugblatt, das sich an die gesamte Bevölkerung wendet und die Motive der Kriegshetzer, die Gefahren des Kriegs und die Friedensinteressen des Proletariats bespricht. Dieses Flugblatt soll der Suggestivkraft kriegerischer Begeisterung und den chauvinistischen Tiraden der bürgerlichen Presse gegenüber aufklärend und ernüchternd wirken. Diese Aktion soll die Massen zum tatkräftigen Widerstand gegen die Kriegshetzer mobil machen. Die Landesversammlung sieht in der raschen Aktion das wirksamste Mittel, in diesem Augenblicke der Völkerverhetzung entgegen zu treten und die Interessen des Völkerfriedens zu wahren. “195

Die Resolution, eine Stellungnahme des Parteivorstands sowie die internationalen Beschlüsse gegen den Krieg veröffentlichten die Stuttgarter Radikalen in der Schwäbischen Tagwacht als Zeichen ihrer kompromisslosen Antikriegshaltung ${ }^{196}$. Am 28. Juli publizierten sie einen Artikel des Göppinger Radikalen August Thalheimer über die „Ziele des österreichischen Angriffs“"197. Am selben Tag organisierten sie zwei Massenversammlungen gegen den Krieg, die sich zu den Beschlüssen der internationalen Sozialistenkongresse bekannten ${ }^{198}$ und anschließend spontan zu Demonstrationszügen formierten und in die Innenstadt marschierten.

Der württembergische Landesvorstand ließ - gemäß dem Beschluss der Landesversammlung - ein Flugblatt gegen den Krieg erstellen. „Gegen den drohenden Weltkrieg!" lautete die Parole; auf zwei Seiten wurde über die Hintergründe und

194 Vgl. Stein (wie Anm. 165) S. 390.

195 „Die Landesversammlung der Sozialdemokraten Württembergs gegen den Krieg“, Schwäbische Tagwacht Nr.171 vom 27.7. 1914. S.1.

196 Vgl. Schwäbische Tagwacht Nr. 171 vom 27.7. 1914. S. 1 f.

197 „Am Rande des Weltkrieges“, Schwäbische Tagwacht Nr. 172 vom 28. 7. 1914. S. 1.

198 Vgl. „Aus Stuttgart“, Schwäbische Tagwacht Nr. 173 vom 29. 7. 1914. S. 3. 
Folgen eines Krieges aufgeklärt und dazu aufgerufen, dem „Kriege den Krieg zu erklären“199.

Verteilt wurde es jedoch nicht mehr. Am 31. Juli wurde der Kriegszustand über ganz Deutschland verhängt; der Landesvorstand stellte daraufhin jegliche Aktionen ein und verbot die Verbreitung der Flugschrift ${ }^{200}$. Keil erklärte rückblickend, er sei der Meinung gewesen, dass, wenn der Mobilmachungsbefehl komme, die Gesinnungsgenossen marschieren würden und müssten. Von den „Phantastereien“, die Sozialisten müssten den Generalstreik ausrufen und den Kriegsdienst verweigern, habe er nie etwas gehalten ${ }^{201}$.

Als am 4. August 1914 die sozialdemokratische Reichstagsfraktion den Kriegskrediten zustimmte, wurden die politischen Gegensätze nunmehr unüberbrückbar. Die Haltung der süddeutschen Abgeordneten war ein entscheidender Faktor für die Beschlussfassung der Fraktion. Diese, die fest entschlossen waren, für die Kriegskredite zu stimmen, bildeten allein schon fast die Hälfte der Fraktion ${ }^{202}$.

Ab Kriegsbeginn überschlugen sich die Ereignisse regelrecht; beide Seiten, Reformisten und Radikale, organisierten sich und versuchten ihren Einfluss zu behaupten. Die Radikalen setzten alles in Bewegung, um über Stuttgart hinaus zu wirken und um die innerparteiliche Opposition reichsweit zu vernetzen. Für den 2. September kündigten sie eine öffentliche Versammlung an, in der Karl Liebknecht zum Thema „Gegen die Annexionshetze“ sprechen sollte ${ }^{203}$. Nachdem das zuständige Wehrkommando diese umgehend verbot, organisierten sie für den 21. September eine nicht-öffentliche Funktionärsversammlung mit Liebknecht. Dort kritisierten die Anwesenden das Abstimmungsverhalten der Reichstagsfraktion. Sie schonten auch Liebknecht nicht mit Kritik „und sprachen unumwunden aus, dass er - auch als einziger - gegen die Kriegskredite hätte stimmen müssen“204. Am Ende beschloss die Versammlung, dass Liebknecht in Zukunft gegen die Kriegskredite stimmen sollte ${ }^{205}$; seine Nein-Stimme am 2. Dezember im Reichstag war somit auch eine unmittelbare Folge des Wirkens der Stuttgarter Radikalen ${ }^{206}$.

199 Weiter hieß es: „Kämpft mit uns für eine freiheitliche Weiterentwicklung der Staatswesen in der Richtung zum Sozialismus, der den Frieden verbürgt und der kapitalistischen Ausbeutung ein Ende bereitet. Der Friede ist das kostbarste Gut des Menschen, das höchste Bedürfnis der Völker! Hoch die internationale Völkerverbrüderung! “; Flugblatt des Landesvorstandes der württembergischen Sozialdemokratie „Gegen den drohenden Weltkrieg!“ HStA Stuttgart P 2 Bü 57 (Nachlass Kurt Schimmel, Ministerialrat 1879-1967).

$200 \mathrm{Vgl}$. Keil (wie Anm. 12) S. $297 \mathrm{f}$.

201 Vgl. Keil (wie Anm. 12) S. 297.

202 Groh (wie Anm. 81) S. 680 f. Der Grund für die Bewilligung der Kriegskredite sei laut Groh zudem gewesen, dass auch die sozialdemokratische Arbeiterschaft „von der Volksbewegung für die Landesverteidigung ergriffen" wurde; ebd. S. 681.

203 Vgl. Walter Bartel: Die Linken in der deutschen Sozialdemokratie im Kampf gegen Militarismus und Krieg. 1958. S. 195.

204 Bartel (wie Anm. 203) S. 195.

205 Vgl. Bartel (wie Anm. 203) S. 196.

206 Karl Liebknecht selbst stimmte mit diesem Beschluss voll überein und gab an, dass die 
Am 4. November eskalierten in der württembergischen SPD schließlich die Auseinandersetzungen. Auf einer Sitzung des Landesvorstandes und des Landesausschusses beschlossen die gemäßigten Sozialdemokraten ohne die Stimmen der Presskommission, Keil als neuen Chefredakteur einzustellen ${ }^{207}$. Dadurch sollte der Einfluss der Linken auf das Landesorgan endgültig unterbunden werden. Diese Maßnahme ging aus Sicht der Linken als „Gewaltstreich des Landesvorstandes“ in die Geschichte ein ${ }^{208}$. Politische Debatten zwischen den Flügeln waren nicht mehr möglich, es überwogen organisatorische Streitigkeiten und ein unversöhnlicher Kampf um den Führungsanspruch über das Landesorgan und die Stuttgarter Parteiorganisation. Die Radikalen Crispien, Walcher und Hörnle verließen die Redaktion. In ihrer Broschüre „Im Kampf um unsere Grundsätze“ formulierten sie ihre Kritik am Landesvorstand, der daraufhin in der Schrift „Der Parteivorstand zum Redaktionswechsel der Schwäb. Tagwacht" antwortete ${ }^{209}$.

Am 21. Dezember erklärten die Kreisvorstandsmitglieder Oster, Schimmel und Anderscheck in der Schwäbischen Tagwacht den Stuttgarter Ortsverein aufgrund fehlender Abrechnungen „als außerhalb des Rahmens der Organisation der Sozialdemokratischen Partei Deutschlands“ stehend ${ }^{210}$. In der Erklärung hieß es, die Stuttgarter Partei sei nicht gewillt, ihre statuarisch festgelegten Verpflichtungen gegenüber dem Kreisverein, der Landes- und der Gesamtpartei einzuhalten ${ }^{211}$. Es folgte der Aufruf an alle Mitglieder, in Zukunft ihre Beiträge direkt an den Kreiskassier Kurt Schimmel abzuführen, da man verhindern müsse, dass vom Stuttgarter Verein Gelder, „die gemäß unserem Statut der Kreis-, Landes- und Zentralkasse gehören, für örtliche Zwecke verwendet werden“ ${ }^{\text {212 }}$.

Daraufhin trat Westmeyer am 23. Dezember aus dem Kreisvorstand zurück ${ }^{213}$. In seiner Rücktrittserklärung erinnerte er den Kreisvorstand an ein Schreiben, in dem die Stuttgarter Parteileitung bereits am 5. Dezember mitgeteilt hatte, dass sich der Verein aufgrund des Krieges und seiner Begleiterscheinungen mit der Abrechnung verspätet habe. Der Kreisvorstand sei deshalb gebeten worden „sich zu gedulden“

Kritik der Stuttgarter für ihn eine große Lehre gewesen sei; vgl. Bartel (wie Anm. 203) S. 196. 207 Vgl. Keil (wie Anm.12) S.313. - Wie in Anmerkung 10 erwähnt, bildeten die Radikalen in der Presskommission die Mehrheit. Der Einstellung Keils als Chefredakteur hätten sie bestimmt nicht zugestimmt.

208 Vgl. Im Kampf um unsere Grundsätze. Tatsachenmaterial zum Gewaltstreich des Landesvorstandes der Sozialdemokraten Württembergs gegen die politische Redaktion der Schwäbischen Tagwacht. 1914. S. 16.

209 Vgl. Der Parteivorstand zum Redaktionswechsel der Schwäb. Tagwacht. Protokoll der Presskommission über die gemeinsame Sitzung am 15. November 1914.

210 „Aus der Partei“, Schwäbische Tagwacht Nr. 297 vom 21.12. 1914. S. 3.

211 „Aus der Partei“, Schwäbische Tagwacht Nr. 297 vom 21.12. 1914. S. 3. - So schildert es auch Keil in seinen Memoiren; vgl. Keil (wie Anm. 12) S. 322.

212 „Aus der Partei“, Schwäbische Tagwacht Nr. 297 vom 21.12. 1914. S. 3.

213 Vgl. Schreiben von Friedrich Westmeyer „An den Kreisvorstand des Württ. I. Wahlkreises“ vom 23.12. 1914. HStA Stuttgart P 2 Bü 6 (Nachlass Kurt Schimmel, Ministerialrat 1879-1967). 
bis die Aufgaben erledigt werden könnten ${ }^{214}$. Westmeyer erklärte, das Vorgehen der Kreisvorstandsmitglieder sei der letzte Akt in dem „wohlorganisierten Kesseltreiben gegen die den Opportunisten nicht gefügige Stuttgarter Organisation“215. Das mache ihm eine Zusammenarbeit mit ihnen für die Zukunft unmöglich ${ }^{216}$.

Die Reformisten gründeten bald darauf mit der Minderheit der Stuttgarter Mitglieder, die sich nicht den Radikalen angeschlossen hatten, einen „Verein zur Förderung der ,Schwäbischen Tagwacht “'217. Sie schufen damit eine eigene Organisation in Stuttgart und vollzogen den ersten Schritt zur organisatorischen Spaltung der Landespartei ${ }^{218}$.

\section{Fazit}

Die dargestellten Entwicklungen zeigen, dass die Spaltung der württembergischen Partei das Ergebnis eines ideologischen Differenzierungsprozesses war, der sich ab 1908 entscheidend zuspitzte. Dabei entzündeten sich an taktischen Fragen der politischen Praxis prinzipielle ideologische Kontroversen, die zur Herausbildung von politischen Strömungen führten: Die Radikalen, die die revolutionäre Umwälzung der kapitalistischen Gesellschaftsordnung anstrebten, und die Reformisten, die den Kapitalismus mittels parlamentarischer Tätigkeit und Reformen schrittweise verändern wollten. Meilensteine dieses ideologischen Polarisierungsprozesses in Württemberg waren dabei Momente der Jahre 1907, 1908, 1910 und 1913.

Während der frühen Massenstreikdiskussionen der Jahre 1904 bis 1906 kamen zwar deutliche Meinungsverschiedenheiten zum Ausdruck, Uneinigkeiten in Prinzipienfragen traten jedoch noch nicht zutage. Die Kontroversen wurden zudem vorrangig zwischen Einzelpersonen ausgetragen - Heymann, Hildenbrand und Sperka lehnten den Massenstreik ab, Clara Zektin hingegen forderte eine eingehende Diskussion darüber als Vorbereitung auf den Ernstfall.

In den Debatten über die Budgetbewilligung der Abgeordneten von 1907 beanstandete erstmals ein Teil der Mitgliedschaft einen Bruch mit sozialdemokratischen Prinzipien, nämlich der Ablehnung eines kapitalistischen Landesetats. Die Versammlungsprotokolle, die ab 1907 detaillierter ausfielen, weisen neben Zetkin und Westmeyer eine Reihe von Mitgliedern auf, die das Verhalten der Fraktion kritisierten (u. a. Behr, Roßmann und Kanser). Dennoch wollte die Mehrheit der Fraktion

214 Westmeyer (wie Anm. 213).

215 Westmeyer (wie Anm. 213).

216 Westmeyer (wie Anm. 213).

217 Vgl. Bergmann/Haible/Iwanowa (wie Anm.15) S. 163.

218 Auf einer Konferenz revolutionärer Sozialdemokraten gründeten die Linken am 21. Februar 1915 dann „eine eigene provisorische ,Landeskommission“"; vgl. Bergmann/Haible/Iwanowa (wie Anm. 15) S. 163. - Zur Spaltung der Landespartei vgl. ebd. S. 201-205. 
kein Misstrauensvotum aussprechen - Keils Einwand überzeugte sie, es habe sich um eine Ausnahme im Hinblick auf den Sozialistenkongress gehandelt. So blieben die Kontroversen im Jahr 1907 formal zwar folgenlos, im Vergleich zur Massenstreikdiskussion erzeugten sie aber eine polarisierte Stimmung in der Landespartei.

Entscheidend für den Differenzierungsprozess der württembergischen Partei wurden die Debatten von 1908. Die badische und bayrische Landtagsfraktion hatten - gemäß einer zuvor getroffenen Vereinbarung zwischen den süddeutschen Abgeordneten - dem Budget zugestimmt. Anders als 1907 war nun die Mehrheit der Stuttgarter Mitgliedschaft der Meinung, die Abgeordneten hätten mit den Prinzipien der Partei gebrochen und verfolgten eine neue Taktik. Im Zuge der Auseinandersetzungen wurden grundlegende Fragen kontrovers diskutiert, die über den konkreten Fall der Budgetbewilligung hinaus gingen: etwa auf welchem Weg der Sozialismus einzuführen sei (s. Redebeiträge Heymann vs. Dr. Duncker). Clara Zetkin warf dabei Heymann vor, wie ein bürgerlicher Reformer zu argumentieren, während dieser den Radikalen vorhielt, sich von persönlichem Hass statt von sachlichen Gesichtspunkten leiten zu lassen. Die Polarisierung wurde deutlich sichtbar; ein reformistischer und ein radikaler Flügel hatten sich gebildet.

Die Mehrheit des Stuttgarter Ortsvereins vertrat nun radikale Positionen und verteidigte diese gegenüber den reformistischen Ansichten der württembergischen Landtagsabgeordneten, die die Mehrheit im Landesvorstand bildeten. Die Versuche der Fraktion, ihren Besuch beim König ein Jahr später zu rechtfertigen, nahm die Stuttgarter Mitgliedschaft nunmehr mit schallendem Gelächter entgegen. Zuerst die Budgetbewilligungen und nun der Hofgang - das war zu viel des Guten; die Stuttgarter Mitglieder nahmen ihre Abgeordneten kaum noch ernst. Als dann im Jahr darauf die badische Fraktion erneut dem Budget zustimmte und die württembergischen Abgeordneten eine Revision des Nürnberger Beschlusses forderten, waren die prinzipiellen Uneinigkeiten nicht zu übersehen. Auch die Massenstreikdebatte in diesem Jahr offenbarte prinzipielle Differenzen, wie sich etwa in den Tagwacht-Artikeln von Hildenbrand und Pannekoek zeigte.

Ein Novum war nun, dass die süddeutschen Abgeordneten den Beschluss von Nürnberg bewusst gebrochen hatten und die württembergische Fraktion eine Revision der Parteibeschlüsse von 1908 forderte. Der reformistische Flügel in der Partei plädierte nun offensiv für eine Änderung parteipolitischer Prinzipien.

Bis zur Bewilligung der Kriegskredite, die den Schlusspunkt dieses Differenzierungsprozesses bildeten, waren die Auseinandersetzungen gekennzeichnet von einem Ringen um Einfluss und von der Unmöglichkeit sich einig zu werden. Ab 1911 wurde etwa heftig um die personelle Besetzung der Tagwacht-Redaktion gestritten $^{219}$, dieser Konflikt war jedoch nicht „Hauptinhalt des Streites ${ }^{\text {“220 }}$ zwischen

219 Siehe Anm. 10. Da der Konflikt eine Folge der politischen Kontroversen war, wird hier nicht auf den genauen Verlauf eingegangen.

220 Hannelore Schlemmer: Die Rolle der Sozialdemokratie in den Landtagen Badens und Württembergs und ihr Einfluß auf die Entwicklung der Gesamtpartei zwischen 1890 und 
Radikalen und Reformisten, sondern eine Folge des ideologischen Streits und damit vielmehr ein „Nebenschauplatz“. Auch trug die radikale Strömung in Württemberg nicht „zunächst rein persönlichen Charakter [...] und [vermischte sich] erst später mit sachlichen Meinungsverschiedenheiten “221. Die Untersuchung der Diskussionsprotokolle zeigt, dass sich der Streit in der Landespartei an sachlichen Meinungsverschiedenheiten entzündete.

Diese äußerten sich bis zur Spaltung noch im Streit um die Antikriegstaktik der Partei. Nach Meinung der Radikalen war die Kriegsgefahr nur durch den revolutionären Sturz des Kapitalismus endgültig abzuwehren, deshalb sollte man beginnen, mit Massenprotesten auf der Straße auf den Umsturz hinzuarbeiten. Die Reformisten stellten einen revolutionären Weg prinzipiell in Frage; ihrer Ansicht nach war die Beeinflussung parlamentarischer Entscheidungen ausschlaggebend. So verteidigten sie im Jahr 1913 die Zustimmung zur Deckungsvorlage, obwohl diese gegen die internationalen Beschlüsse der Sozialdemokratie verstieß; sie waren überzeugt, dadurch eine - wenn auch nur kleine - Verbesserung für die Arbeiterschaft zu erlangen, nämlich die Verhinderung von indirekten (und „ungerechten“) Steuern.

Das „marxistisches Zentrum“ um Karl Kautsky, das sich in der Reichspartei aus dem linken Flügel herauslöste und damit zu einer „Dreiteilung“ der Sozialdemokratie führte, formierte sich in Württemberg nicht. Hier verhärteten sich die Fronten zwischen Radikalen und Reformisten; dabei schlossen sich die Radikalen den Linken um Rosa Luxemburg an. Die Polarisierung in Radikale und Reformisten erfolgte nicht nur in Stuttgart, sondern in der gesamten Landespartei. Die Trennungslinie vollzog sich auf Landesebene vor allem zwischen städtisch und ländlich geprägten Ortsvereinen. Die Debatten über die Budgetbewilligung und den „Hofgang“ zeigen, dass ländlich geprägte Ortsvereine dem Kurs der Landtagsabgeordneten und des Landesvorstands folgten und für den Radikalismus der Stuttgarter Genossen, der auch in anderen städtischen Vereinen dominierte, nicht zu begeistern waren. Auch die in der Darstellung aufgeführten Resolutionen ländlicher Ortsvereine zu einzelnen Streitpunkten oder Parteitagsbeschlüssen belegen diesen Trend ${ }^{222}$.

Innerhalb des Stuttgarter Ortsvereins ist die politische Entwicklung Wilhelm Keils bemerkenswert, ist sie doch ein unmittelbarer Ausdruck der scharfen Polarisierung in der Stuttgarter Partei. Zunächst noch Befürworter des Massenstreiks, schloss Keil seine Anwendung bereits 1906 für Süddeutschland aus. Die Budgetbewilligung von 1907 unterstützte er, schloss sich jedoch nicht den reformistischen Kräften um Hildenbrand und Heymann an, und betonte, er befürworte keines-

1914. 1953. S. 119. - Zur Charakterisierung der Entwicklungen durch Schlemmer vgl. ebd. S. $115-124$.

221 Schlemmer (wie Anm. 220) S. 120.

222 So etwa die bereits erwähnte Billigung der Budgetbewilligung im Jahr 1908 durch die Ortsvereine Schwenningen, Hall, Reutlingen, Ehningen, Vaihingen und Nürtingen. 
wegs eine prinzipielle Änderung der bisherigen Taktik. Der Bruch zwischen Reformisten und Radikalen im Jahr darauf zwang Keil, sich offen für die eine oder die andere Seite zu positionieren. Die gesamte Stuttgarter Mitgliedschaft hatte klar Stellung bezogen und orientierte sich dabei entweder an den Radikalen um Westmeyer und Zetkin oder an den Landtagsabgeordneten. Mit einer „Zwischenposition" wie zuvor, hätte Keil sich politisch isoliert.

So unterzeichnete er auf dem Nürnberger Parteitag die Erklärung der süddeutschen Abgeordneten, tat dies aber, laut seinen Memoiren, nicht mit voller Überzeugung. Mit der Zuspitzung der Kontroversen ab 1908 wurde Keil glühender Verfechter der reformistischen Richtung. Als Chefredakteur der Schwäbischen Tagwacht stand er schließlich inmitten der Auseinandersetzungen um die Ausrichtung des Parteiblatts. Mit seiner erneuten Benennung zum Chefredakteur im November 1914 erreichten die Reformisten schließlich die Ausschaltung des Einflusses der Linken genau durch jenen Mann, der unter ihren Reihen zuvor der wankelmütigste gewesen war. Die Entwicklung Wilhelm Keils, der 1905 in Jena noch gemeinsam mit Clara Zetkin für den Massenstreik stimmte und später die Parteibeschlüsse von 1910 als „Pyrrhussieg“ des „Hyperradikalismus“ ${ }^{\text {"223 }}$ bezeichnete, zeigt, dass es für die Mitglieder nur ein Entweder-Oder geben konnte.

Doch warum konnte sich der Stuttgarter Ortsverein als radikale Hochburg etablieren?

Ein wichtiger Faktor war gewiss die sozio-ökonomische Lage der Stuttgarter Arbeiterschaft. Anders als die „Arbeiterbauern“ in den ländlichen Gebieten Württembergs arbeiteten sie in Großbetrieben, verfügten oftmals über kein Grund und Boden und mussten einen Großteil ihres Lohnes für die Miete aufbringen. Die Studie Theodor Leiparts von 1900 weist nach, dass die soziale Lage oftmals mit der politischen Orientierung korrelierte ${ }^{224}$; so verzeichneten die Tabakarbeiter mit 51,2 Prozent den höchsten gewerkschaftlichen Organisationsgrad - jene Gruppe, die den niedrigsten Lohn aufzuweisen hatte und den niedrigsten „Hauszins“, was auf sehr bescheidene Wohnverhältnisse deutet.

Bedeutend für die politische Ausrichtung der Mitgliedschaft war bestimmt auch der Einfluss führender Persönlichkeiten wie Westmeyer und Zetkin. Doch die Radikalisierung der Mitgliedschaft war nicht hauptsächlich das Ergebnis „geschickter Agitation“, der „Verbissenheit“ und des „Feuers“225 der Radikalen. Die reformistischen Sozialdemokraten verteidigten ihre Meinung nicht minder feurig und konsequent, insofern stießen die radikalen Wortführer in Stuttgart auf eine durchaus ernstzunehmende Konkurrenz.

Die Untersuchung der Diskussionen zeigt, dass die Mehrheit der Stuttgarter Mitglieder sich den Radikalen anschloss, als im Jahr 1908 die württembergische

${ }^{223}$ Keil (wie Anm. 12) S. 220.

224 Vgl. dazu Leipart (wie Anm. 17).

225 Schlemmer (wie Anm. 220) S. 115. 
Landtagsfraktion die Budgetbewilligung in Baden und Bayern zu rechtfertigen suchte. Neben den bereits genannten Faktoren war entscheidend für die Radikalisierung der Stuttgarter, dass die Mehrheit der Mitgliedschaft im Verhalten der Abgeordneten einen Bruch mit ideologischen Prinzipien sah, den sie nicht bereit war zu billigen ${ }^{226}$.

Man stritt dabei um praktische, konkrete Fragen, die die württembergische Mitgliedschaft direkt betrafen. Es ging nicht um irgendwelche sozialdemokratische Abgeordnete, die hier mit den Prinzipien der Partei brachen, sondern um ihre „eigenen“, die sie selbst aufgestellt und gewählt hatten und für die sie sich unter Umständen auch vor anderen rechtfertigen mussten. Die Mitglieder entwickelten dabei klare Positionen und eine genaue Vorstellung dessen, was sie von ihren Abgeordneten verlangten. Sie waren überzeugt davon, dass die Parlamentsarbeit der Fraktion nicht alternativlos war. Erst jetzt (und nicht etwa während der Budgetbewilligungsdebatte von 1907) waren sie bereit, sich unter der Führung der radikalen Wortführer dem reformistischen Kurs der Landtagsabgeordneten zu widersetzten.

Die Spaltung der Sozialdemokratie im Jahr 1915, als Ergebnis eines ideologischen Differenzierungsprozesses zwischen 1904 und 1914, war zunächst nicht absehbar. Wohl kaum ein Sozialdemokrat hätte sich auf dem Dresdener Parteitag erträumt, dass seine Partei, die „im besten Sinne des Wortes revolutionär ist“227, jemals den Kriegskrediten zustimmen würde. Der Verlauf der späteren Ereignisse zeigt, dass mit der Spaltung der württembergischen Partei im Jahr 1915 und der Reichspartei im Jahr 1917 die Kontroversen noch lange nicht beigelegt wurden. Sowohl Parteilinke als auch Vertreter des marxistischen Zentrums, ferner Revisionisten wie Eduard Bernstein und Kurt Eisner schlossen sich der USPD an. Nicht die prinzipiellen Kontroversen bildeten die Trennungslinien zwischen SPD und USPD, sondern der Streit über die Bewilligung der Kriegskredite und den eingegangenen

${ }^{226}$ Christ-Gmelin vertritt die Meinung, das Auftreten theoretisch geschulter „NichtWürttemberger“, die „anti-reformistisch prädisponiert" gewesen seien, sei der entscheidender Faktor für die Radikalisierung des Stuttgarter Ortvereins gewesen; Christ-Gmelin (wie Anm.6) S. 184. - Dem kann nur bedingt zugestimmt werden. Bestimmt waren die Erfahrungen von Clara Zetkin in Sachsen und jene Westmeyers in Niedersachsen andere als etwa die Hildenbrands im württembergischen Knittlingen. Und mit Sicherheit war die Rolle Zetkins und die Westmeyers herausragend, was allein an ihren vielen Wortbeiträgen ersichtlich wird. Doch von politischen Prädispositionen auszugehen erscheint deshalb irreführend, weil ein zwangsläufiger Zusammenhang zwischen politischer Umgebung und politischer Meinung suggeriert wird, der in anderen Fällen nicht nachzuweisen ist. Wie wäre dann Wilhelm Keil einzuordnen, der erst mit 26 Jahren aus der Nähe von Kassel nach Stuttgart kam, ein Alter in dem man durchaus politisch „prädisponiert“ sein kann? Und warum war Jacob Walcher aus Wain in Württemberg nicht „reformistisch prädisponiert" oder wenigstens offen für die reformistische Agitation der Landtagsabgeordneten? Er trat 1906 der Sozialdemokratie bei, zu einem Zeitpunkt, in dem die Radikalen noch nicht den Ortsverein dominierten.

227 Protokoll über die Verhandlungen des Parteitages der Sozialdemokratischen Partei Deutschlands. Abgehalten zu Dresden vom 13. bis 20. September 1903. 1903. S. 133. 
Burgfrieden ${ }^{228}$. So bildeten die Stuttgarter Linken u. a. mit Rosa Luxemburg innerhalb der USPD eine eigene Strömung, die „Gruppe Internationale“, später „Spartakusbund“, die an Silvester 1918 schließlich Mitbegründerin der Kommunistischen Partei Deutschlands (KPD) wurde ${ }^{229}$.

228 Vgl. Potthoff/Miller (wie Anm. 1) S. 78 f.

229 Vgl. Potthoff/Miller (wie Anm. 1) S. 98. 